\title{
Patient-controlled sedation in procedural care
}

\author{
Andreas Nilsson
}

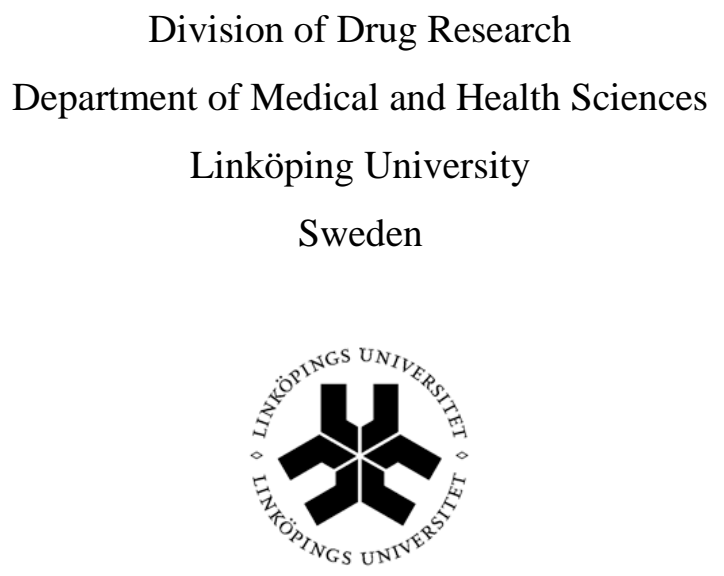

\section{Linköping University}

FACULTY OF HEALTH SCIENCES

Linköping 2015 
C)Andreas Nilsson

Published articles have been reprinted with the permission of the copyright holder.

Printed in Sweden by LiU-Tryck, Linköping 2014

ISBN 978-91-7519-221-5

ISSN 0345-0082 
Till Malin, Alvar och Valter

"I want to be loved, or at least admired" R. Gyllenhammar 


\section{Supervisors}

Lena Nilsson, MD, PhD, Associate Professor

Department of Medical and Health Sciences

Linköping University, Sweden

Folke Sjöberg, MD, PhD, Professor

Department of Clinical and Experimental Medicine

Linköping University, Sweden

Eva Uustal, MD, PhD

Department of Clinical and Experimental Medicine

Linköping University, Sweden

\section{Opponent}

Lars I. Eriksson, $\mathrm{MD}, \mathrm{PhD}$, Professor

Department of Physiology and Pharmacology

Karolinska Institutet, Sweden

Committee board

Jan Jakobsson, MD, PhD, Professor

Department of Clinical Science, Intervention and Technology

Karolinska Institutet, Sweden

Anna-Clara Spetz, MD, PhD, Associate Professor

Department of Clinical and Experimental Medicine

Linköping University, Sweden

Zoltan Szabo, MD, PhD, Associate Professor

Department of Medical and Health Sciences

Linköping University, Sweden 


\section{Contents}

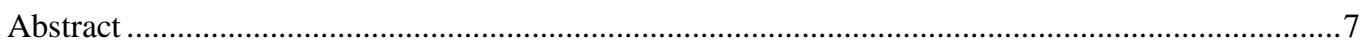

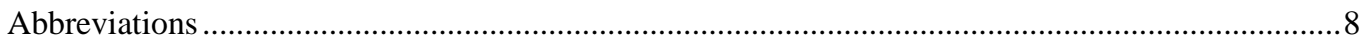

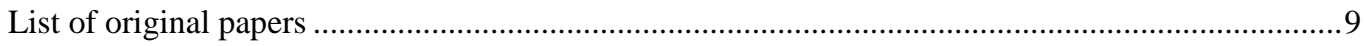

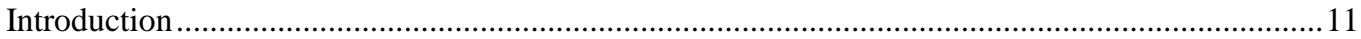

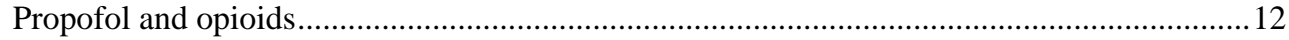

Patient-controlled sedation (PCS) ……………………………………………………...15

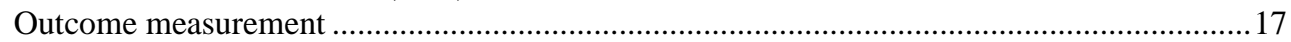

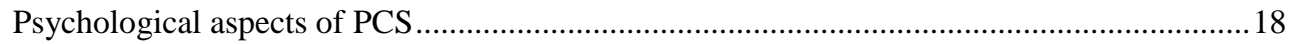

Monitoring during moderate sedation ………………………..........................................19

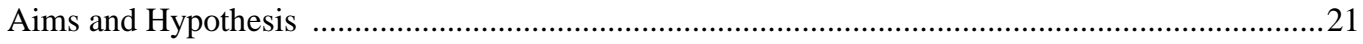

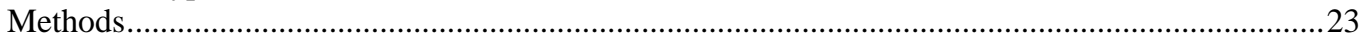

Variables and clinical assessments ..............................................................................23

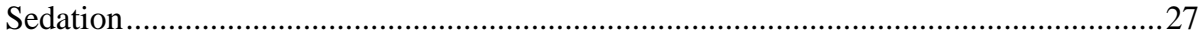

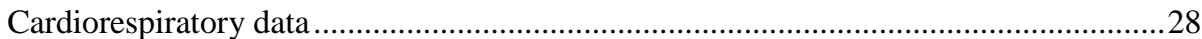

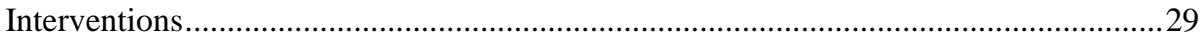

Patients' preference and experiences .........................................................................29

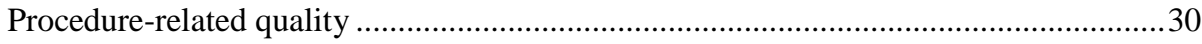

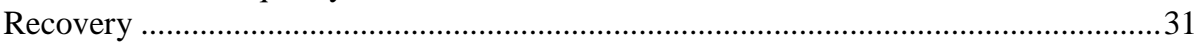

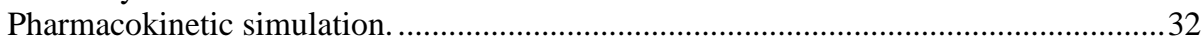

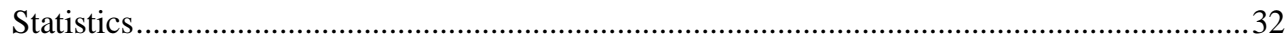

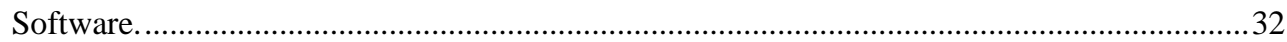

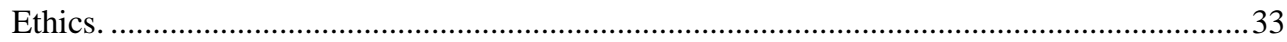

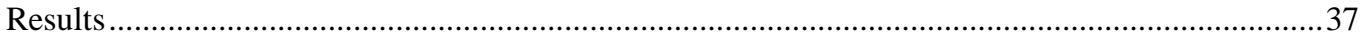

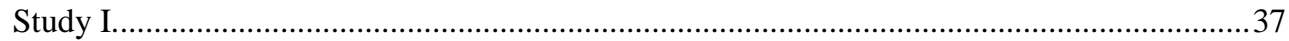

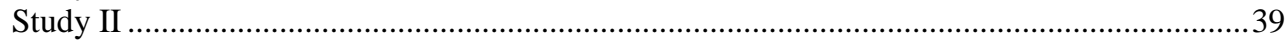

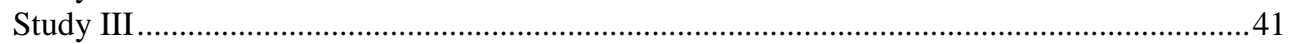

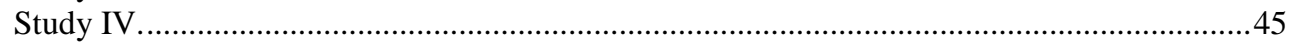

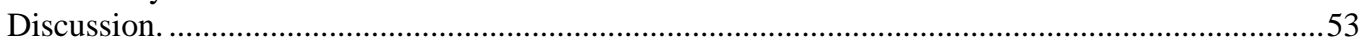

Patients' preference and experiences..........................................................................53

Cardiorespiratory function and interventions....................................................................56

Level of sedation and patients' use of PCS. ......................................................................61

Procedure characteristics and recovery ……………………………………………….....63

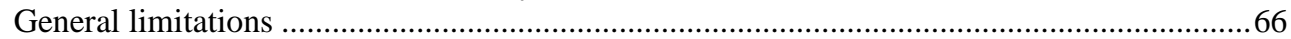

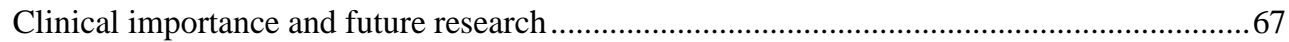

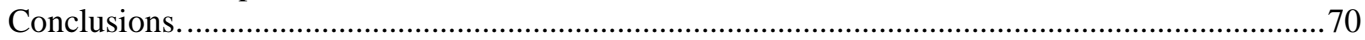

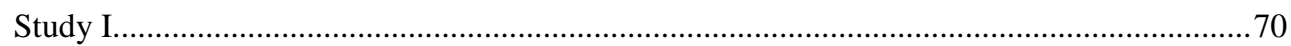

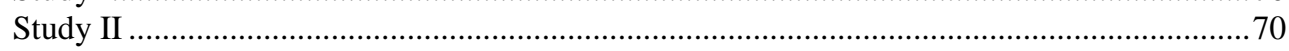

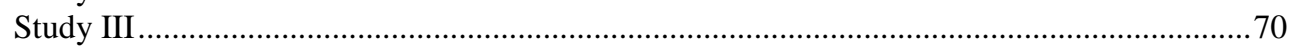

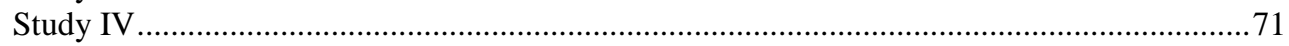

General conclusions...................................................................................................

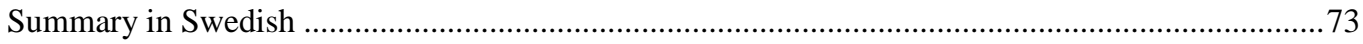

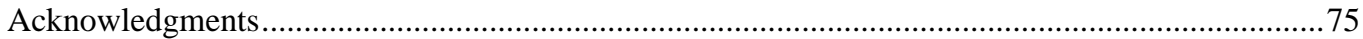

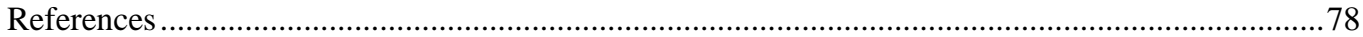





\section{Abstract}

The need for procedural sedation is extensive and on the increase in numbers of patients. Minor treatments or diagnostic procedures are being performed with inadequate sedation or even without any sedatives or analgesics. Also, sedation techniques that support advanced, high-quality, in-patient care procedures representing easy performance and rapid recovery are requested for increased effectiveness. In this doctoral thesis, patient-controlled sedation (PCS) using propofol and alfentanil for surgical and diagnostic procedures was studied. The overall aim was to study aspects of safety, procedural feasibility and patients' experiences. The main hypothesis was that PCS using only propofol is a safe and effective method for the induction and maintenance of moderate procedural sedation. The studies included were prospective, interventional, and in some cases, randomized and double-blinded.

Data on cardiopulmonary changes, level of conscious sedation (bispectral index and Observer's assessment of alertness/sedation [OAA/S]), pain, discomfort, anxiety, nausea (visual analogue scales), interventions performed by nurse anaesthetists, surgeons' evaluation of feasibility, procedure characteristics, recovery (Aldrete score) and pharmacokinetic simulation of concentrations of drugs at the effect site supported the analysis and comparison between PCS and anaesthetist-controlled sedation and propofol PCS with or without alfentanil.

PCS can be adjusted to cover a broad range of areas where sedation is needed, which, in this thesis, included burn care, gynaecological out-patient surgery and endoscopic procedures for the diagnosis and treatment of diseases in the bile ducts (endoscopic retrograde cholangiopancreatography $[\mathrm{ERCP}])$. PCS for burn wound treatment demands the addition of alfentanil, but still seems to be safe. PCS was preferred by the patients instead of anaesthetist-controlled sedation. The addition of alfentanil to PCS as an adjunct to gynaecological surgical procedures also using local anaesthesia increases the surgeon's access to the patients, but impairs safety. Apnoea and other such conditions requiring interventions to restore respiratory function were seen in patients receiving both alfentanil and propofol for PCS. Patients' experiencing perioperative pain and anxiety did not explain the effect-site concentrations of drugs. Different gynaecological procedures and patients' weights seemed to best explain the concentrations. For discomfort and pain during the endoscopic procedure (ERCP), propofol PCS performs almost the same as anaesthetistperformed sedation. Overall, as part of the pre-operative procedures, PCS does not seem to be time-consuming. In respect to the perioperative perspective, PCS supports rapid recovery with a low incidence of tiredness, pain, and post-operative nausea and vomiting (PONV).

The data suggest that PCS further needs to be adapted to the patient, the specific procedure and the circumstances of sedation for optimal benefit and enhanced safety. 


\section{Abbreviations}

ACS Anaesthetist-controlled sedation

ASA American Society of Anesthesiologists classification

BIS Bispectral index

$\mathrm{C}_{\mathrm{e}} \quad$ Concentration at effect site

CRF Case report form

ECG Electrocardiography

EEG Electroencephalography

ERCP Endoscopic retrograde cholangiopancreatography

GABA Gamma-amino butyric acid

IV Intravenous

OAA/S Observer's assessment of alertness and sedation

PONV Post-operative nausea and vomiting

$\mathrm{PCO}_{2} \quad$ Partial pressure of carbon dioxide

PCS Patient-controlled sedation

PK Pharmacokinetic

$\mathrm{P}_{\mathrm{tc}} \mathrm{CO}_{2} \quad$ Partial pressure of transcutaneous carbon dioxide

RR Respiratory rate

$\mathrm{SpO}_{2} \quad$ Peripheral capillary oxygen saturation

TCI Target-controlled infusion

TVT Tension free vaginal tape 


\section{List of original papers}

The studies will be referred to by their roman numerals.

I Patient-controlled sedation using a standard protocol for dressing changes in burns: Patients' preferences, procedural details and a preliminary safety evaluation Andreas Nilsson, Ingrid Steinvall, Zoltan Bak, Folke Sjöberg. Burns 2008;34:929-934

II Alfentanil and patient-controlled propofol sedation - facilitate gynaecological outpatient surgery with increased risk of respiratory events

A. Nilsson, L. Nilsson, E. Uustal, F. Sjöberg. Acta Anaesthesiol Scand 2012:56(9):1123-9.

III Should propofol and alfentanil be combined in patient-controlled sedation? A randomised controlled trial using pharmacokinetic simulation and regression models

Andreas Nilsson, Lena Nilsson, Thomas Schnider, Eva Uustal, Folke Sjöberg Submitted

IV Sedation during endoscopic retrograde cholangiopancreatography:

A randomised study of patient-controlled propofol sedation and that given by a nurse anaesthetist

Andreas Nilsson, Benjamin Grossmann, Eva Uustal, Folke Sjöberg, Lena

Nilsson

Submitted 


\section{Introduction}

The use of sedation is recommended when patients have to tolerate procedures involving pain, anxiety or discomfort. Sedation can also be used to simplify procedures that require a patient's co-operation or minimal movement. The different stages of sedation through the continuum of depth are achieved by giving sedatives or anaesthetics. The different levels of sedation are described as minimal sedation (anxiolysis), moderate sedation, deep sedation and general anaesthesia (Table 1); larger doses or combinations of different sedatives or analgesics deepen the level of sedation [1].

Table 1: Continuum of depth of sedation according to the American Society of Anesthesiologists [1]

\begin{tabular}{|c|c|c|c|}
\hline $\begin{array}{l}\text { Minimal sedation } \\
\text { (anxiolysis) }\end{array}$ & $\begin{array}{l}\text { Moderate sedation } \\
\text { (conscious sedation) }\end{array}$ & Deep sedation & General anaesthesia \\
\hline $\begin{array}{l}\text { Responds to verbal } \\
\text { stimulation } \\
\text { Unaffected airway } \\
\text { Spontaneous } \\
\text { ventilation } \\
\text { Unaffected cardiac } \\
\text { function }\end{array}$ & $\begin{array}{l}\text { Purposeful response } \\
\text { to verbal or tactile } \\
\text { stimulation } \\
\text { Adequate airway, } \\
\text { respiration and } \\
\text { usually maintained } \\
\text { cardiac function }\end{array}$ & $\begin{array}{l}\text { Purposeful response } \\
\text { following repeated or } \\
\text { painful stimulation } \\
\text { May require airway } \\
\text { intervention } \\
\text { Respiration may be } \\
\text { inadequate } \\
\text { Cardiac function } \\
\text { usually maintained }\end{array}$ & $\begin{array}{l}\text { Not arousable even } \\
\text { with painful stimulus } \\
\text { Often requires airway } \\
\text { intervention } \\
\text { Frequently inadequate } \\
\text { spontaneous } \\
\text { ventilation } \\
\text { Cardiac function may } \\
\text { be impaired }\end{array}$ \\
\hline
\end{tabular}

If a procedure requires moderate sedation, the ability to rescue patients from deep sedation must be ensured [2]. Benzodiazepines, propofol or opioids are often used solely or in combination to achieve a proper level of sedation. Since the need for procedural sedation is extensive, especially in outpatient care and for smaller procedures, guidelines are designed to ensure that non-anaesthesiologists provide 
their patients with appropriate sedation for diagnostic and therapeutic procedures with the lowest possible risk [2,3]. European guidelines recommend using fast- and short-acting drugs and monotherapy, and avoiding the use of IV-achieved pain relief [3]. Sedation from midazolam and opioids were earlier the standard, but for more than a decade and for a variety of procedures, the use of propofol has been welldocumented for endoscopy [4-6], dental treatment [7-9], renal stone therapy [10-12] and emergency care [13-16].

\section{Propofol and opioids}

The fast onset of propofol results from the rapid distribution in highly perfused tissues and from its high solubility in fat. A quick redistribution from the central to the peripheral areas decreases the concentration of propofol in the blood within minutes and, as distribution continues, the concentration of the drug in the brain falls. Infusion of propofol for conscious sedation results in dose-dependent anxiolysis, sedation and amnesia [17] through the interactions between GABA and the $\mathrm{GABA}_{\mathrm{A}}$ receptor [18]. The use of any sedative, alone or together with an opioid, may be associated with serious side effects and adverse events, [19, 20]. Propofol displays a narrow therapeutic window, and minor dose adjustments may lead to affected vital signs [21]. Propofol use causes dose dependent and speed of injection dependent effects. At the start of anaesthesia, induction leads to apnoea in more than one in four cases, the incidence of which increases if opioids are added [22]; infusion of propofol results in decreases in tidal volume and respiratory frequency [23]; systolic blood pressure decreases [24] and is associated with a cardiac depressant effect and a decrease in systemic vascular resistance [25]. Propofol may also cause upper airway collapsibility and obstruction, especially when patients transition from conscious to unconscious [26]. 
Opioids are given in addition to sedatives for pain control. By binding to the subtypes of opioid receptors, they inhibit nociceptive reflexes and release neurotransmitters. Opioids demonstrate different actions of pain treatment and other effects; stimulation of mu receptors produces supraspinal analgesia, euphoria and decreased ventilation. Stimulation of the kappa receptors produces sedation, miosis, and spinal analgesia. Besides spinal analgesia, the delta receptor modulates the activity of the mu receptors [27]. Opioids display a great inter-individual variability in response and dose requirements. Both pharmacokinetic, e.g. metabolizing enzymes, and pharmacodynamic, e.g. tachyphylaxia, factors contribute to the fine balance between pain control and sedation with or without the absence of other clinical effects, such as respiratory depression or bradycardia [28]. Analgesia from opioids are dosedependent; at high doses, they will relieve any pain, although less effectiveness is seen in neuropathic pain [29].

The opioid alfentanil has a rapid onset and short duration of action. Less lipid soluble than other opioids, its rapid action is instead caused from the small volume of distribution, thereby resulting in a quick equilibration of concentration over the blood-brain barrier [30]. The large person-to-person variability results in differences in the doses of alfentanil required between individuals [31]. To achieve moderate sedation, alfentanil is usually combined with propofol. Compared to alfentanil and propofol given together, alfentanil solely administered to patients undergoing endoscopic procedures has advantages of less interventions, such as adjustments of dosing, treatment for bradycardia/hypertensions, manipulations of airways, as well as fewer changes in vital signs and more rapid recovery [32].

Pharmacokinetic modelling describes the relationship between dose and the concentration, for example in plasma or at the effect site. Compartment models represent a mathematical calculation of the different volumes in the physical body where the drug is distributed. The three compartment model describes how a drug is 
equilibrated between three different physiological volumes (Figure 1). Drug administration to the central compartment leads to a slow and a fast equilibration between two other compartments. Times for equilibrations are described from constants and metabolic clearance continuously decreases the concentration of the drug from the central compartment [33].

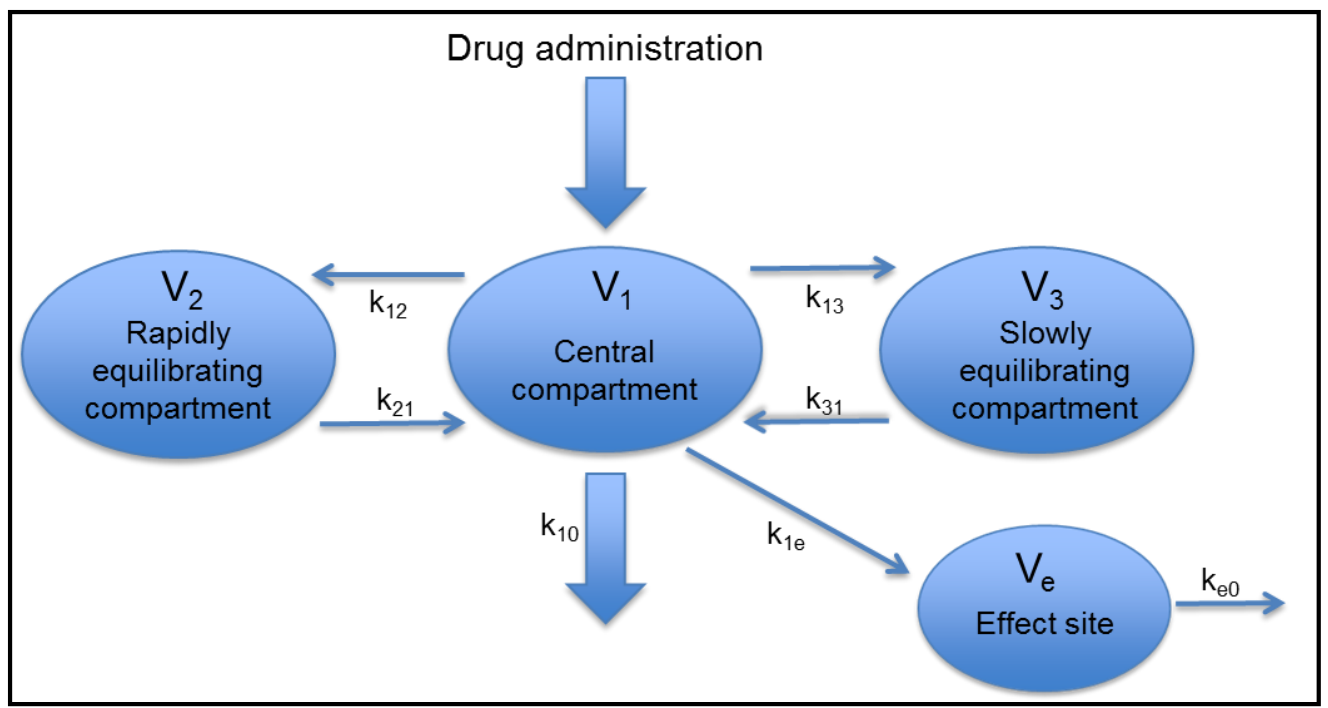

Figure 1. A three compartment model including the effect site. V: volume; k: constant

Safety evaluations of combined sedatives or opioids added to sedatives have been issued; adding midazolam to propofol has been suggested to decrease the dosage of propofol and the incidence of adverse events (hypotension, oxygen desaturation) during gastroscopy [34]; a German evaluation of the outpatient practice of gastroenterology, including 24441 patients, states that 112 minor events (hypoxemia the most common) occurred most frequently in patients who were solely sedated with propofol compared to those receiving propofol and midazolam [20]. However, there is also evidence and recommendations for retained safety with the use of propofol only [35]. 


\section{Patient-controlled sedation (PCS)}

The concept of PCS allows the patient to administer drugs according to their experienced need for sedation. The choice of drug or drugs and the number or size of permitted bolus doses makes the system adaptable to different situations. Usually the patient starts to press the delivery button to achieve anxiolysis or moderate sedation before the diagnostic or therapeutic procedure is started. During the procedure, the patient is allowed to continue administering the sedative according to the need for comfort. After several doses have been delivered, the patients usually become too sedated to demand repeated doses. When propofol is used, this demonstrates the period of safety inbuilt in the PCS concept since the effect of the given drug is diminished. When the concentrations of the drug are decreased or the stimuli of the patients are enhanced, the patients are enabled to proceed administering doses. A variation of pharmacology and programming possibilities makes PCS adjustable to suit the specific demands of many procedures.

Studies on PCS have addressed issues of safety [36, 37], patients' experiences [36, 38 , 39], programming of pumps, and procedural details [37, 40]. However, most studies are rather limited in the number of participants and show limitations in study design. When unpleasant/painful procedures are located outside ordinary anaesthesia and operation facilities, specific circumstances for high safety, quality and comfort arise.

PCS is not a strictly defined system. It is a method of sedation in which the included parts, such as doses, infusion rate, lock-out periods, drugs, can be adjusted according to the situation, but the actual decision of administering a dose is the patient's choice. A draft of PCS was described by Galletly et al. (1989) [41] who gave two patients in an intensive care unit the option to self-administer midazolam to decrease discomfort and anxiousness during a period of being intubated for mechanical ventilation 
treatment. Both patients decreased their experienced levels of anxiety from high to minimal. PCS is a relative young field for research. Park et al. (1991) [42] stated that PCS using midazolam and fentanyl during surgical epidural anaesthesia was ranked higher by patients than sedation provided by anaesthetists. Rudkin et al. (1991) [43] initiated the use of propofol PCS for patients undergoing third molar extraction under local analgesia and showed that doses of propofol were dependent on the duration of the procedure and the difficulty of the surgery. In comparison to the use of midazolam and fentanyl, the authors identified less of a decrease in cognitive function. Cook et al. (1993) [44] studied PCS without the use of programmed time periods where no doses could be delivered and, thereafter, most studies have been using this open system (zero lock-out) for PCS. In contrast, patient-maintained sedation (1999) [45] is sedation according to a set estimated target concentration of the drug (target controlled infusion [TCI]) where the patient can adjust the system to increase the steady state concentration of the drug. The two techniques have also been combined (2011) using TCI for baseline sedation and PCS for additional doses of propofol according to the patient's extra demand of anxiolytics [46]. For the past decades, evaluation of PCS has focused on these early identified areas, the patients' preference for different techniques to diminish stress, and finding a suitable system for a variety of procedures. Attention has been drawn to questions concerning safety and effectiveness as there is an increased demand for procedural sedation, but yet in a cost-conscious manner.

For PCS, propofol is the golden standard for sedation. Since 1991 [47], questions of feasibility and safety have been assessed using propofol as a sole agent or using opioids as adjuncts. This early study comparing propofol PCS to sedation from midazolam/fentanyl given by anaesthetists has become less relevant over time. It is of increasing interest to demonstrate if PCS provides adequate conditions for procedure performance in comparison to propofol sedation controlled by nurse-/anaesthetists. 
An overview of drugs used for PCS in comparison to anaesthetist-controlled sedation and outcome measurements for the last decade are displayed in Table 2.

Table 2: An overview of drugs used for PCS in comparison to anaesthetist-controlled sedation and outcome measurements for the last decade

\begin{tabular}{|c|c|c|c|c|}
\hline Author & PCS & ACS & Procedure & Outcome measurements \\
\hline Mazanikov et al. 2013 [48] & $P$ & TCI P & ERCP & $\begin{array}{l}\text { Doses of propofol and } \\
\text { additional alfentanil, } \\
\text { adverse events, recovery, } \\
\text { ease of performance, } \\
\text { patient's satisfaction }\end{array}$ \\
\hline Joo et al. 2012 [49] & $\mathrm{P}$ and $\mathrm{P} / \mathrm{A}$ & & Breast biopsy & $\begin{array}{l}\text { Dose-dependent efficacy, } \\
\text { adverse events }\end{array}$ \\
\hline Bell et al. 2010 [50] & $\mathrm{P}$ & $\mathrm{P}$ & Procedures at ED & Safety, effectiveness \\
\hline Mandel et al. 2010 [51] & $\mathrm{P} / \mathrm{R}$ & $\mathrm{P} / \mathrm{R}$ & Colonoscopy & $\begin{array}{l}\text { Respiratory rate, level of } \\
\text { sedation, interventions }\end{array}$ \\
\hline Nilsson et al. 2008 [52] & $\mathrm{P} / \mathrm{A}$ & $\mathrm{P} / \mathrm{F}$ & $\begin{array}{l}\text { Burn wound } \\
\text { care }\end{array}$ & $\begin{array}{l}\text { Patient's satisfaction, } \\
\text { safety }\end{array}$ \\
\hline Agostini et al. 2007 [53] & $\mathrm{P} / \mathrm{F}$ & $\mathrm{M} / \mathrm{Pe}$ & GI endoscopy & $\begin{array}{l}\text { Effectiveness, safety, } \\
\text { patient's satisfaction }\end{array}$ \\
\hline Lok et al. 2002 [54] & $\mathrm{P} / \mathrm{A}$ & $\mathrm{D} / \mathrm{Pe}$ & $\begin{array}{l}\text { Oocyte } \\
\text { retrieval }\end{array}$ & $\begin{array}{l}\text { Safety, patient's acceptance, } \\
\text { procedural effectiveness }\end{array}$ \\
\hline
\end{tabular}

ACS: anaesthetist-controlled sedation; A: alfentanil; D: diazepam; ED: emergency department; ERCP: endoscopic retrograde colangiopancreatography; F: fentanyl; GI: gastrointestinal; M: midazolam; P: propofol; Pe: pethidine; R: remifentanil; TCI: target-controlled infusion

\section{Outcome measurement}

Outcome measurements from dosing, failure and safety have been reported; Table 2 summarises some common choices of drugs and endpoints. Procedure-related quality 
has usually been evaluated in terms of efficiency or time periods in comparison to a standard sedation regimen. In most cases, PCS has been evaluated as at least equal to the standard: number of oocytes retrieved for in vitro fertilization [54], differences in procedure time and difficulty of performance [53], and surgeons' satisfaction [46]. VAS scaling or Likert scales have aided the evaluation of satisfaction from both patients' and physicians' $[55,56]$ perspectives. Doses used for PCS are rather similar, as measured in $\mathrm{mg}$ per demand or $\mathrm{mg} / \mathrm{kg}$ per dose demand. Doses of propofol vary from $4.8 \mathrm{mg}$ as a single bolus dose with zero lock-out [57], via doses of $20 \mathrm{mg}$ including $1 \mathrm{~min}$ lock-out [50], to $0.25 \mathrm{mg} / \mathrm{kg}$ per demand [58]. PCS is considered a valid method for procedural sedation, but is not applicable for every patient; problems in communicating and learning may contribute to less functionality [35]. A Cochrane meta-analysis of sedation for colonoscopy concluded that regardless of inferior pain control, PCS showed higher patient satisfaction [59].

\section{Psychological aspects of PCS}

To some extent, patient's acceptance of PCS can be understood through studies on pain and controllability. If a painful stimulus can be modified within an individual, some feelings of being in control are perceived. Simply the act of pressing a button can be as potent as receiving an analgesic [60]. Additionally, anticipation of pain may lead to an increased experience of pain [61, 62]. The ability to reduce or amplify nociception seems to differ widely across individuals. Psychological testing may predict whether or not PCS will be successful, as it is more likely to be accepted among those who tend to adapt to an internal control, rather than among those who think that their lives are controlled by others. Thus, the importance of a sense of control and its correlation to satisfaction with PCS have been deemed significant [56, 63]. 
PCS can be described as a link between an individual's experienced level of comfort and pain and the ability to adjust for these experiences, including a built-in feedback system. The concept of PCS can be described by aggressiveness (speed for achievement of control) and robustness (activity to adjust sedation/analgesia that degrades the patient's vital signs) [64]. Aggressiveness and robustness are in most cases linked; with limited aggressiveness comes decreased robustness. Most of the pumps used for PCS are programmed to deliver doses according to the patients' demands without adjustment for prior demands. One exception that tried to separate aggression and robustness was presented for shock wave lithotripsy using PCA with alfentanil. An Ohmeda 9000 pump was programmed to adjust the size of the bolus and basal infusion according to the history of demand activity [65]. Although this is a novel design of the PCS model, this study did not attract followers.

\section{Monitoring during moderate sedation}

Monitoring of cardiopulmonary changes provoked from sedation is usually recommended and consists of pulse oximetry, non-invasive blood pressure measurements and ECG [2,3]. Depending on the intended level of sedation and the ASA status of the patient, the recommendations may differ. Evaluation of evidence for safe procedural sedation for endoscopy recommend the use of ECG in selected cases, if the patient displays a history of cardiac and/or pulmonary disease. Visual detection of respiratory failure or apnoea is not a reliable method. Capnographic monitoring may contribute to enhanced safety, but since the clinical advantage is uncertain, it is not recommended [35]. However, a later study revealed a $26 \%$ decrease in the incidence of hypoxemia and a $50 \%$ decrease in the incidence of

severe hypoxemia $\left(\mathrm{SpO}_{2}<85 \%\right)$ when capnography was used [66]. Electroencephalography (EEG) seems to recommend less propofol being administered during prolonged procedures, though the clinical safety benefit of EEGbased monitoring seems dubious [35]. 
Methods for evaluating the level of sedation include a somewhat subjective assessment of verbal/physical responses from a patient given sedatives (sedation scales) and the clinical evaluation of electrical brain activity (EEG). Sedation scales such as the Observer's assessment of alertness and sedation scale (OAA/S) [67] or the Ramsay scale [68] help to target the aimed level of sedation, which is usually moderate sedation [35]. Moderate sedation achieved by the use of propofol or other sedatives provides high levels of safety [69] and patient satisfaction [70]. EEG monitoring via the bispectral index (BIS) has been reported to correlate well with levels of responsiveness during sedation from propofol [71]. Responsiveness was measured from the OAA/S (level 5: alert, responds readily to name spoken in normal tone to level 0: does not respond to noxious stimuli). BIS levels of 50 or less indicate that the patients are unconscious and levels of 75 indicate moderate sedation and low probability of recall [72]. 


\section{Aims and Hypothesis}

The overall aim of this thesis was to study aspects of safety, procedural feasibility and patients' experiences from PCS for surgical and diagnostic procedures.

The main hypothesis was that PCS using only propofol is a safe and effective method for the induction and maintenance of moderate procedural sedation.

Study I aims:

- To evaluate the patients' preference for PCS or sedation given by anaesthetists in connection with dressing changes in burns.

- Per-operative evaluation of changes in cardiorespiratory functions and differences in levels of sedation.

Study II aims:

- To compare per-operative cardiorespiratory functions, level of sedation, and need for anaesthetic interventions between patients using propofol PCS or propofol PCS with the addition of alfentanil during gynaecological surgery.

- To study surgical limitations and number of aborted procedures, as a consequence of insufficient sedation and the role of the addition of alfentanil. 
Study III aims:

- To analyse the pharmacokinetic profiles of propofol and alfentanil from the use of PCS.

- To analyse variables from the surgical procedures and patients' characteristics that could explain the concentrations of propofol at the effect site.

Study IV aims:

- Evaluation of safety, procedure characteristics, patients' experiences, and recovery of propofol PCS for ERCP as an alternative to moderate propofol sedation administered by nurse anaesthetists or midazolam sedation handled by the ERCP team. 


\title{
Methods
}

\begin{abstract}
All included studies are designed to be prospective and randomized. They cover a broad field of diagnostic, surgical and treatment procedures, involving both men and women of different ages and co-morbidity (ASA I to III). One double-blinded study is presented in two papers (Studies II and III) with different perspectives and outcomes. The four surveys were planned to focus on sedation involving diverse and specific challenging issues. Table 3 displays the content of the studies involved.
\end{abstract}

\section{Variables and clinical assessments}

The possibility to evaluate safety, in strict terms defined as morbidity/mortality, is limited within the situation for the chosen subject. Instead, issues of safety are analysed from surrogate endpoints, such as data from cardiorespiratory functions, doses of drugs and specific safety interventions made by nurse-/anaesthetists. 


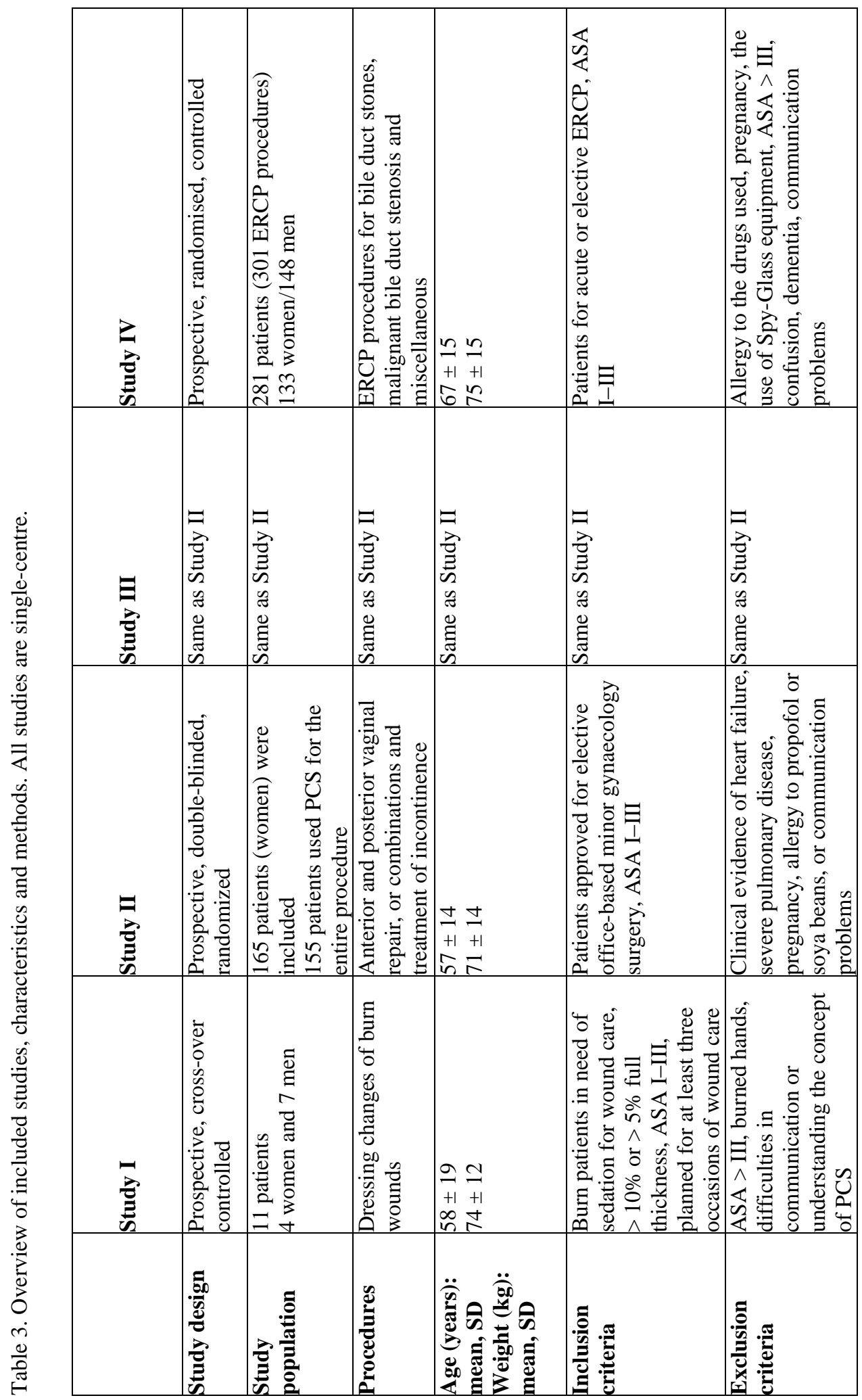




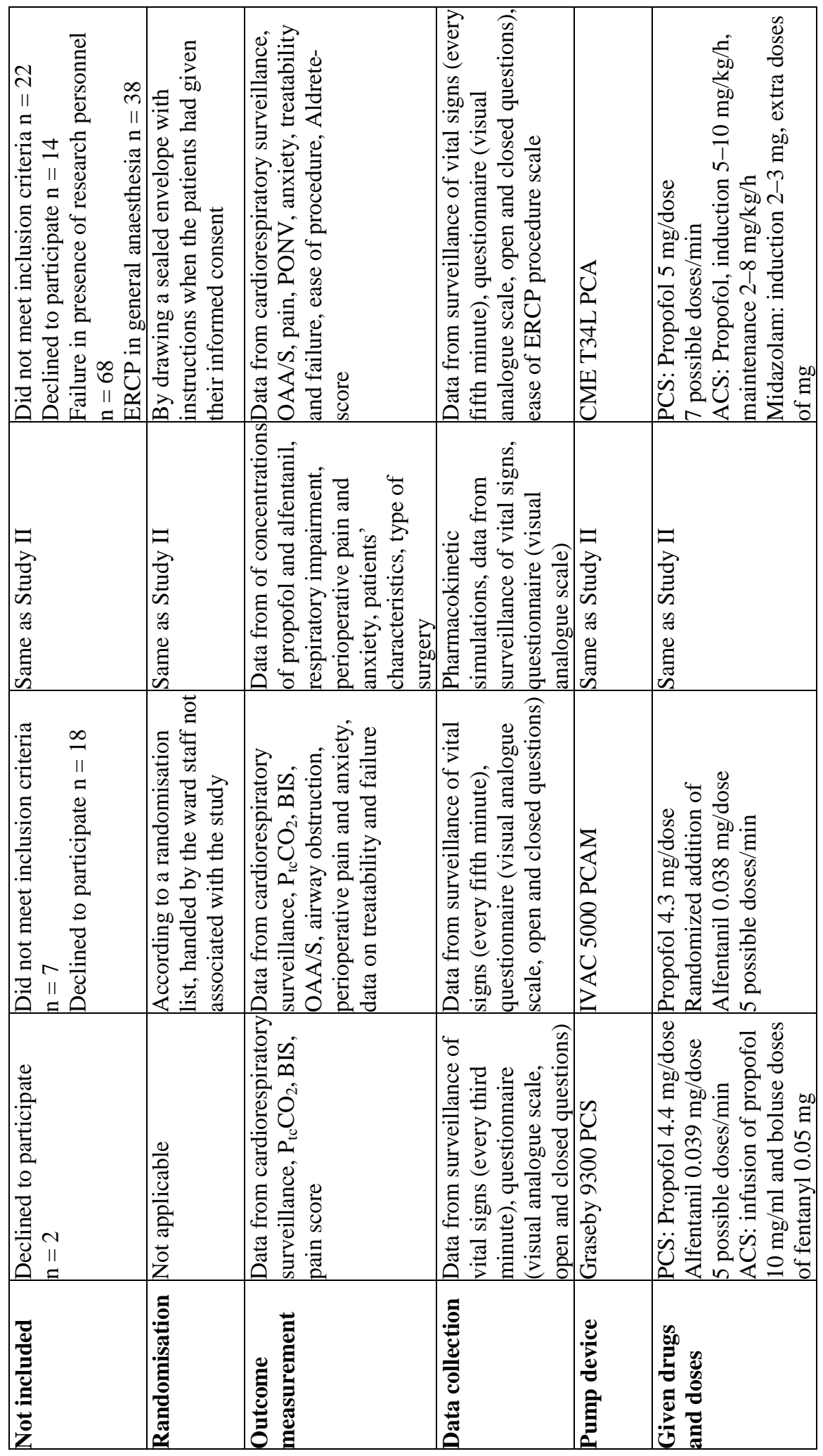




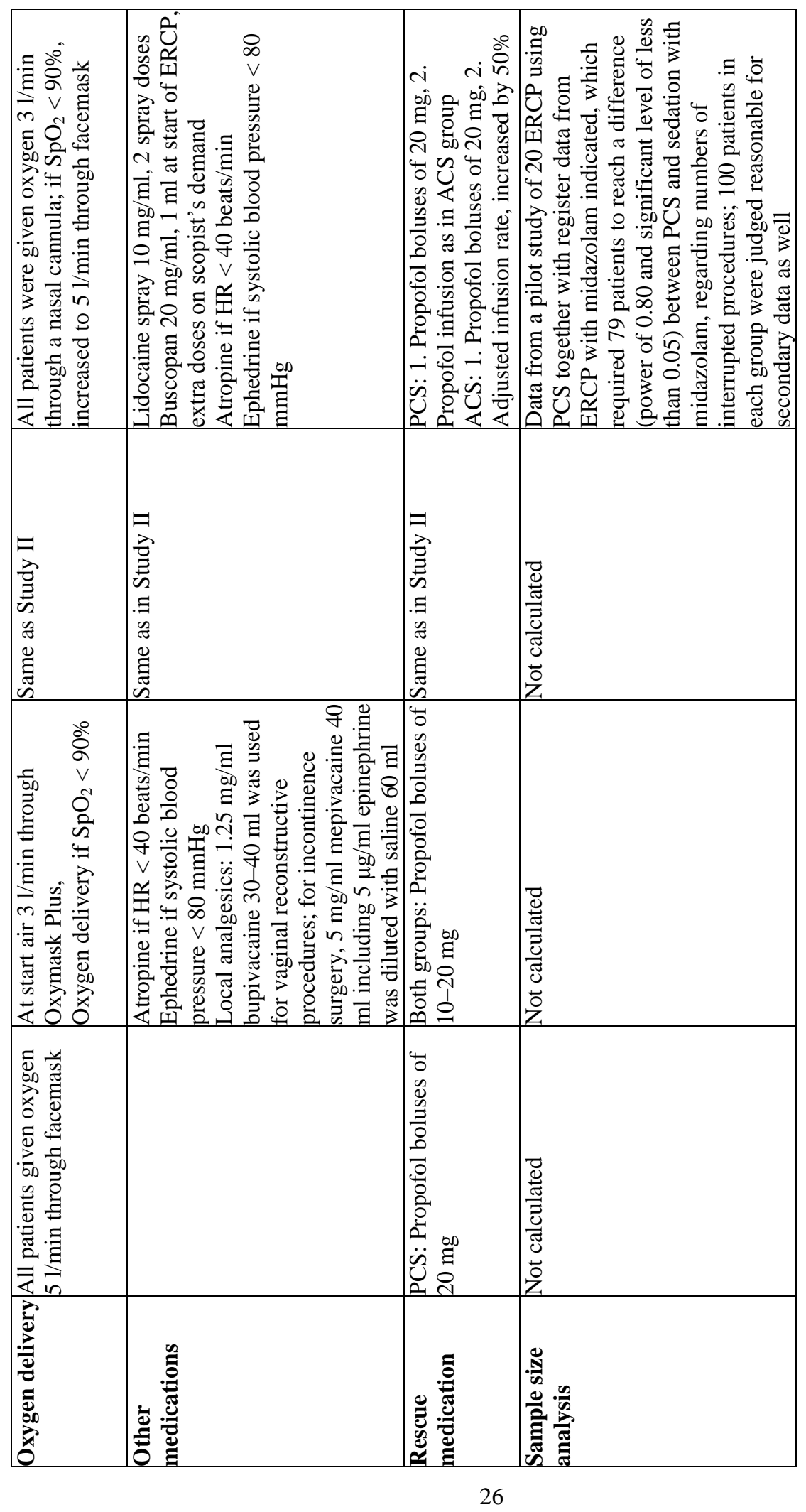




\section{Sedation}

Studies I-II: Bispectral index (A-2000 BIS ${ }^{\mathrm{TM}}$ Aspect Medical Systems, Natick, MA, USA) was used to support non-stimuli affirmed episodes of deep sedation. For that purpose, BIS is highly valid and accurate, and is addressed as a useful method to measure the depth of sedation produced by propofol [71, 73]. Movements, muscle contractions, inaccurate electrode placement and loss of electrodes may lower the level of validity and reliability. Collection of data was continuous and mean BIS values collected every fifth minute were used for data analysis.

Studies II and IV: Observer's assessment of alertness/sedation (OAA/S) scale [67] was also used to identify episodes of over-sedation (Table 4). By using a scale where the clinician interacts with patients can interfere with obtaining the data; however, measuring verbal responses is an easy and accurate way of assessing the depth of sedation. The explicit target for sedation via PCS in the present studies was to maintain the patients at a communicating level (correspond to OAA/S level 5-3), without episodes of deep sedation or unconsciousness (OAA/S level 2-0). Data were collected every fifth minute. 
Table 4. Observer's assessment of alertness/sedation (OAA/S) scale

\begin{tabular}{|l|l|l|l|l|}
\hline Responsiveness & Speech & Facial expression & Eyes & Ncore \\
\hline Readily to normal tone & Normal & Normal & 5 \\
\hline $\begin{array}{l}\text { Lethargic to normal } \\
\text { tone }\end{array}$ & Mild slurring & Mild relaxation & Glazed or mild & 4 \\
\hline $\begin{array}{l}\text { Responds only after } \\
\text { loud/repeated calling }\end{array}$ & Slurring & Marked relaxation & $\begin{array}{l}\text { Glazed and marked } \\
\text { ptosis }\end{array}$ & 3 \\
\hline $\begin{array}{l}\text { Responds only after } \\
\text { mild prodding or } \\
\text { shaking }\end{array}$ & $\begin{array}{l}\text { Few recognized } \\
\text { words }\end{array}$ & Marked relaxation & Glazed & 2 \\
\hline $\begin{array}{l}\text { No response to mild } \\
\text { prodding or shaking }\end{array}$ & No words & Marked relaxation & Glazed & 1 \\
\hline $\begin{array}{l}\text { No response to noxious } \\
\text { stimuli }\end{array}$ & & & & 0 \\
\hline
\end{tabular}

\section{Cardiorespiratory data}

Studies I-II: Perioperative monitoring consisted of pulse oximetry, non-invasive blood pressure measurements, ECG, respiratory rate, end-tidal carbon dioxide (IntelliVue MP30 Philips Healthcare, Best, the Netherlands), and transcutaneous carbon dioxide (TCM-3 TINA, Radiometer, Copenhagen, Denmark).

Study IV: Perioperative monitoring consisted of pulse oximetry, non-invasive blood pressure measurements, ECG and respiratory rate (IntelliVue MP30 Philips Healthcare, Best, the Netherlands),

Studies II and IV: Obstruction of the airway was evaluated by the nurse anaesthetist using a grading of 1 to $3(1=$ clear and patient talking, $2=$ snoring, and $3=$ obstructed).

In Study I, the patients were given oxygen routinely, but in Studies II and IV, administration of oxygen was given in cases of decreased oxygen saturation $\left(\mathrm{SpO}_{2}<\right.$ 
90\%). For administration of air/oxygen and the sampling of $\mathrm{CO}_{2}$, Oxymask Plus provides data that, to some extent, is comparable to arterial analysis of carbon dioxide [74]. In Study IV, supplemental oxygen was given using a nasal catheter. Baseline values were recorded at five-minute intervals.

\section{Interventions}

Study II and IV: Registration of type and number of anaesthetic interventions was used to contribute to a safety analysis. Pre-set limits were used to define the outer acceptable limitations for the vital signs, and also to define when the present nurse/anaesthetists were going to intervene. Therefore, standardized interventions to restore impaired vital signs were not arbitrarily performed: 1) at a respiratory rate less than 8 breaths/minute, patients were encouraged to breathe; 2) oxygen saturation of less than $90 \%$ was treated with an oxygen flow of $3 \mathrm{~L} /$ minute; 3 ) an obstructed airway was handled with chin lift; 4) > 30-second episodes of apnoea were handled with ventilation by mask; 5) bradycardia of less than 40 beats/minute were treated with atropine $0.5 \mathrm{mg}$; 6) systolic blood pressure less than $90 \mathrm{mmHg}$ were treated with ephedrine $5 \mathrm{mg}$; 7) if conditions for surgery or ERCP were impaired or impossible, patients were encouraged to make multiple pushes on the delivery button to deepen the sedation (for patients in Study IV who were given propofol by a nurse anaesthetist, propofol infusion was increased by $50 \%$ after $20 \mathrm{mg}$ of propofol); and 8) if surgical access continued to be impaired, supplementary doses of propofol 10-20 mg were given (Study II).

\section{Patients' preferences and experiences}

Study I: The patients' preference for PCS or traditional sedation was evaluated from the choice of sedation they had prior to the third dressing change, after having had one ACS procedure and one using PCS. 
The visual analogue scale (VAS; $0=$ none to $100=$ the worst experience) was used to obtain data on postoperative nausea or vomiting, pain (Studies I-IV), tiredness, and the patient's overall comfort during the procedure (VAS; $0=$ none to $100=$ excellent). Data was collected by questionnaire; the patients were also asked if they would like to have the same type of sedation in the future and why (Studies II, IV).

\section{Procedure-related quality}

Data on conditions for performing the treatment, and information about dosing received from the PCS pump were also collected. Patients' and procedure characteristics were collected (Studies I-IV). All pre-, per- and post-operative periods were registered in minutes (Studies I, II and IV). During the perioperative period, time for preparing the patients for surgery, induction time, time from start-to-stop of surgery and the ability of surgical performance were collected to understand the efficiency and conditions for surgery and sedation (Studies II and IV). Study II: the surgeons estimated the adequacy of access and visibility using a four-point scale: $1=$ procedure done with no limitations of view or access; $2=$ some limitations, but they did not influence the operation's quality, speed or both; $3=$ view and access limited to the extent that the operation's quality, speed or both were influenced; and $4=$ operation not possible.

Study IV: The ease of the ERCP procedure was evaluated by the endoscopists using a structured questionnaire [40] covering six aspects of its performance: 1. Ease of introduction of endoscope; 2. Patient cooperation during procedure; 3. Retching/vomiting; 4. Cough; 5. Belching; 6. Defence reaction. Every aspect was evaluated using four levels: none (1), minimal (2), moderate (3) and marked (4). 


\section{Recovery}

Study IV: Aldrete score, Table 5 [75], aided the recording of different time periods of recovery; with a score of $\geq 7$, patients were transferred from the ERCP unit to the ward for further recovery. An Aldrete score of $\geq 9$ indicated full recovery.

Table 5. The Aldrete score

\begin{tabular}{|c|c|}
\hline Parameters & Score \\
\hline \multicolumn{2}{|l|}{ Activity: able to move voluntarily or on command } \\
\hline Moving all four extremities & 2 \\
\hline Moving two extremities & 1 \\
\hline Not able to move any extremity & 0 \\
\hline \multicolumn{2}{|l|}{ Respiration } \\
\hline Able to breathe deeply and cough freely & 2 \\
\hline Dyspnoea, shallow or limited breathing & 1 \\
\hline Apnoeic & 0 \\
\hline \multicolumn{2}{|l|}{ Circulation } \\
\hline $\mathrm{BP} \pm 20 \mathrm{~mm}$ of $\mathrm{Hg}$ of pre-anaesthetic level & 2 \\
\hline $\mathrm{BP} \pm 20-50 \mathrm{~mm}$ of $\mathrm{Hg}$ of pre-anaesthetic level & 1 \\
\hline $\mathrm{BP} \pm 50 \mathrm{~mm}$ of $\mathrm{Hg}$ of pre-anaesthetic level & 0 \\
\hline \multicolumn{2}{|l|}{ Level of consciousness } \\
\hline Fully awake & 2 \\
\hline Arousable on calling & 1 \\
\hline Not responding & 0 \\
\hline \multicolumn{2}{|l|}{$\mathrm{O}_{2}$ saturation } \\
\hline Able to maintain $\mathrm{O}_{2}$ saturation $>92 \%$ on room air & 2 \\
\hline Needs $\mathrm{O}_{2}$ inhalation to maintain $\mathrm{O}_{2}$ saturation $>90 \%$ & 1 \\
\hline $\mathrm{O}_{2}$ saturation $<90 \%$ even with $\mathrm{O}_{2}$ supplementation & 0 \\
\hline
\end{tabular}

BP: blood pressure 


\section{Pharmacokinetic simulation}

Study III: The pharmacokinetic simulation (performed by Professor Thomas Schnider) was based on the dosing history recorded with the PCS pump (the time that the fixed boluses were given). For propofol, the pharmacokinetic models described by Schnider et al. [76, 77] that use age, height, weight, and sex as covariates were used. The pharmacokinetic profiles of alfentanil were simulated from the model described by Scott et al. [78], which was scaled by weight. For both drugs, the concentrations at the effect site $\left(\mathrm{C}_{\mathrm{e}}\right)$ were calculated with the software program Excel (Microsoft Corporation) using an Add-In (PKPD Tools for Excel' http://www.pkpdtools.com/doku.php/excel:start).

\section{Statistics}

Descriptive and analytic statistical tests were used for the different parts of the data in the four studies. In Study II-IV, data were displayed in histograms and normal distribution or not was evaluated from the Kolmogorov-Smirnov and Lilliefors tests. Details of the appropriate tests are listed in Table 6. A p-value $<0.05$ was considered significant.

\section{Software}

Excel (Microsoft) was used to organise the data collected from the case report form (CRF).

To aid the statistical analysis, Statistica versions 6-10 (StatSoft Inc, Tulsa, OK, USA) were used. 


\section{Ethics}

All studies were approved by the Regional Ethics Review Board in Linköping and written informed consent was provided by each patient. Every patient was given both oral and written information, and all patients were given the opportunity to ask questions and time for consideration. Before starting Study I, PCS had been described as preferred by patients, but the reason for sedation in many studies was considered less demanding (less pain and anxiety) in comparison to burn care. No studies could be found that had evaluated the preference from the patients' active choice; patients were asked what they would have preferred in the case of repeated treatment.

All patients (Studies I, II and IV) were informed that an anaesthetist or nurse anaesthetist would intervene if they regretted their consent or if they needed support. Only a few patients declined before and during the studies. All personal data were processed, analysed and published de-identified. 


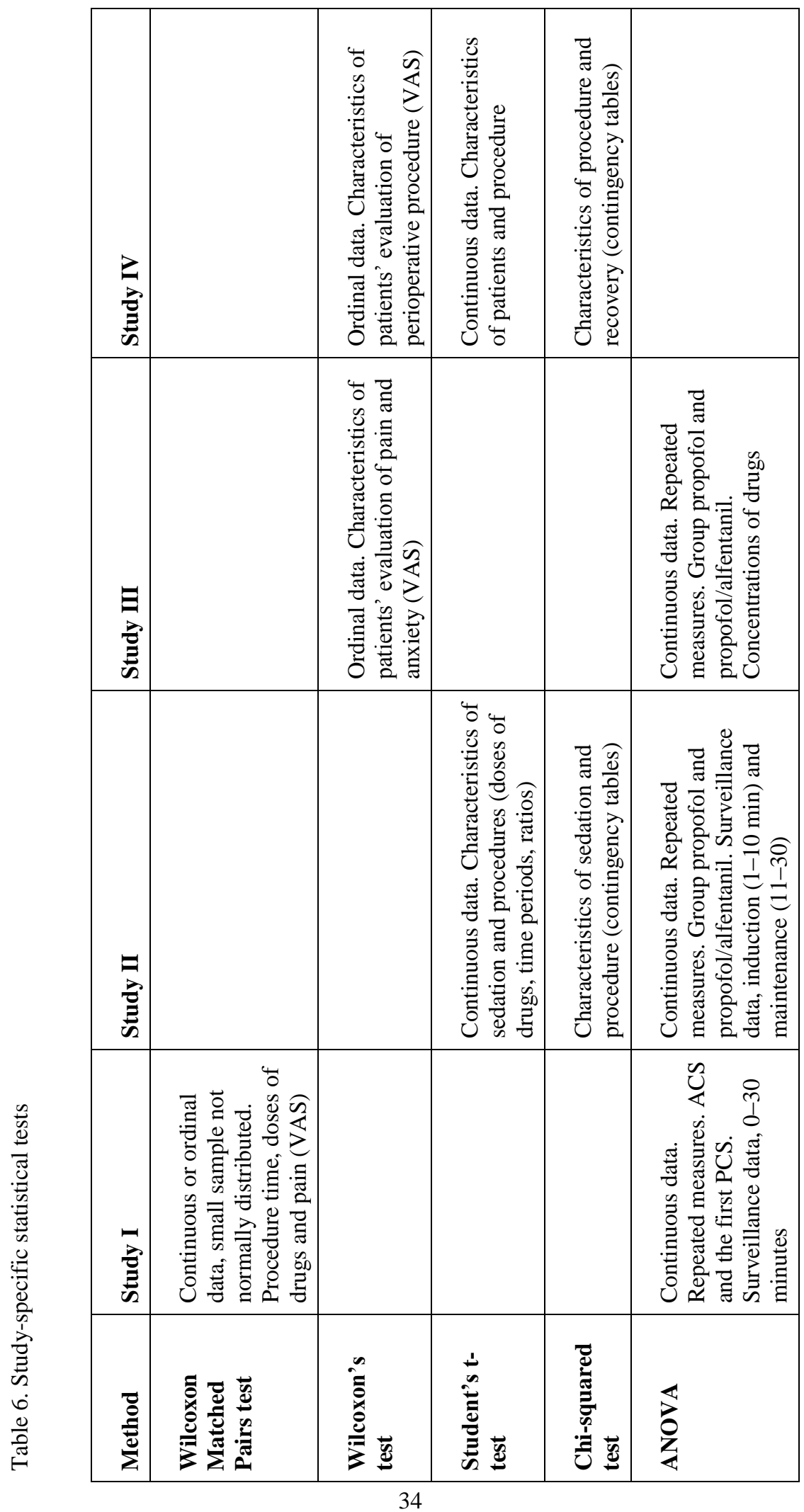




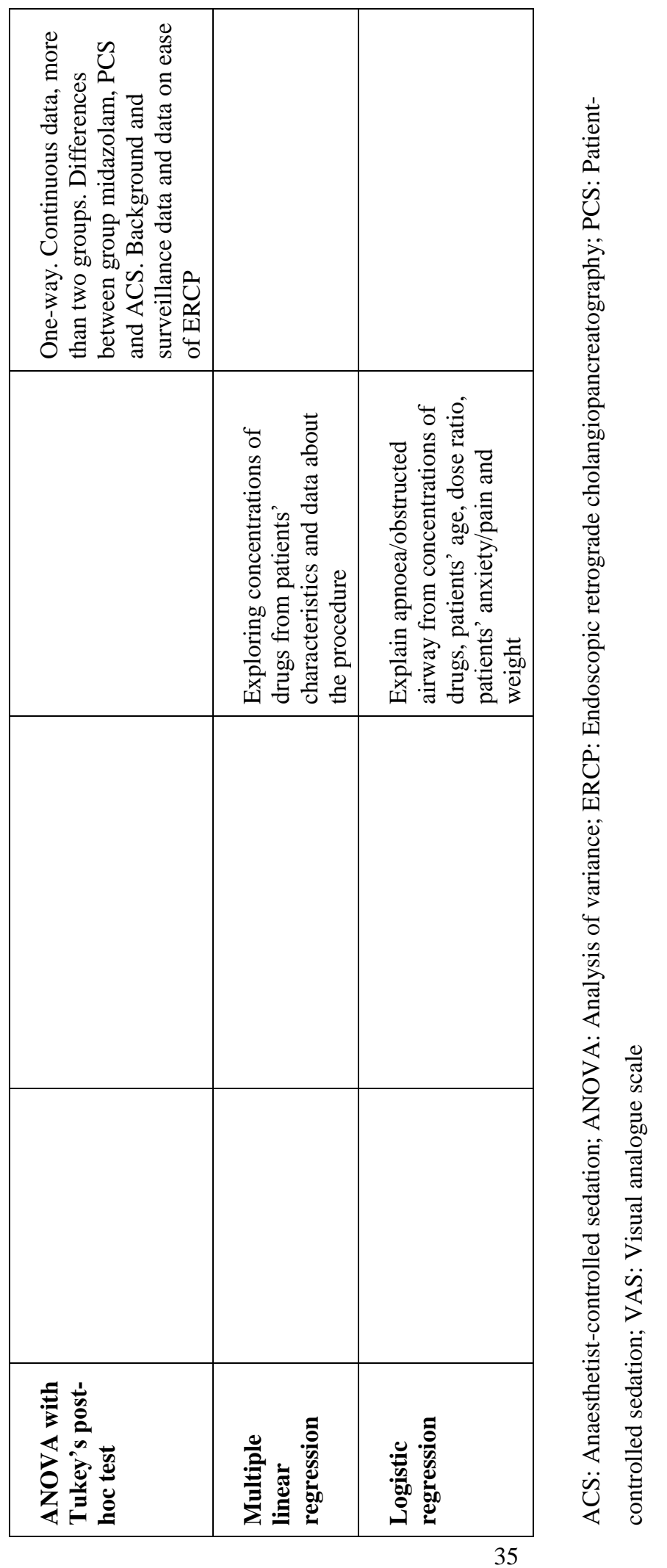




\section{Results}

\section{Study I}

Study I included 11 patients who chose PCS instead of ACS for the third, and sometimes also the fourth, dressing changes; for the initial two dressing changes, sedation had been given by anaesthetists followed by the use of PCS the second time. One patient was indifferent to the techniques but finally chose PCS. One reason for choosing PCS was that the patients appreciated the sense of control - they could administer or refrain from administering doses from the pump. Six patients appreciated the quick recovery, without the sense of drowsiness and coldness. Table 7 summarises the experiences from PCS and ACS, and thereby explores the reasons for choosing PCS.

None of the patients were able to use the full capacity of the pump (due to multiple dose demands when the pump administered doses). Four patients had a ratio between demanded and delivered doses that exceeded 3:1; this means they were given less than a third of the doses they demanded. Two of these patients were not satisfied with the pump capacity. 
Table 7. Patients' perioperative experiences from the different sedation techniques during burn wound care (numbers of answers).

\begin{tabular}{|l|l|l|}
\hline Experiences from sedation & $\begin{array}{l}\text { PCS } \\
\mathbf{n}=\mathbf{1 1}\end{array}$ & $\begin{array}{l}\text { ACS } \\
\mathbf{n}=\mathbf{1 1}\end{array}$ \\
\hline Peroperative pain, VAS > 3 & 7 & 1 \\
\hline Postoperative pain, VAS > 3 & 4 & 4 \\
\hline $\begin{array}{l}\text { Peroperative discomfort, VAS } \\
>3\end{array}$ & 1 & 1 \\
\hline Quick recovery & 7 & 4 \\
\hline Postoperative coldness & 2 & 5 \\
\hline Postoperative drowsiness & 1 & 5 \\
\hline Sense of safeness & 10 & 10 \\
\hline Sense of control & 10 & 2 \\
\hline PONV & 1 & 4 \\
\hline Pain from IV injection & 5 & 2 \\
\hline
\end{tabular}

PONV: postoperative nausea and vomiting; IV: intravenous

Experiences from pain (perioperative), sense of control and PONV were closed choices in the questionnaire given to the patients and the rest of the answers were categorized as above.

During the second wound care procedure when the patients were using PCS for the first time, all patients requested lower doses of drugs than they were given by the anaesthetists: $194 \pm 84 \mathrm{mg}$ of propofol compared to $395 \pm 131 \mathrm{mg}$ during ACS. Mean procedure time did not differ between the first and second dressing procedure (ACS 69 min compared to PCS $68 \mathrm{~min} ; \mathrm{p}=0.86$ ). Propofol doses per minute of procedure time did differ: $6.1(2.1) \mathrm{mg} / \mathrm{min}$ and $2.9(1.3) \mathrm{mg} / \mathrm{min}, \mathrm{p}<0.001$.

Differences in the levels of sedation were found in the data from the BIS monitors, showing that ACS led to significantly more heavily sedated patients $(\mathrm{p}=0.027)$ within the first 30 minutes of wound care. After the induction, before initiating 
wound care, the mean BIS index was 84 (11) for the ACS group and 93 (5) for the PCS group. ACS produced at least two BIS index recordings less than 70. Reduction in the BIS index also occurred during PCS with six recordings of less than 80 .

Changes in physical functions during the first 30 minutes of sedation were also different between the groups. PCS gave higher mean $\mathrm{SpO}_{2}$ concentrations and lower $\mathrm{P}_{\mathrm{tc}} \mathrm{CO}_{2}$. During ACS, there was a slight decrease in saturation $(<90 \%)$ in two cases;

the lowest respiratory rate was 8 . Blood pressure (MAP) was reduced during both ACS and PCS, with the lowest values during ACS between 50\% and 68\% of the baseline. Equivalent data during PCS showed no saturation value lower than $94 \%$ and no respiratory rate less than 10 . The lowest MAP recordings were within $60 \%$ and $96 \%$ of baseline.

\section{Study II}

For the 155 patients who used PCS for the entire procedure, sedation was divided into two different periods: the first period covered the induction (1-10 $\mathrm{min})$ and the second period the first part of the sedation maintenance (11-30 min). For some patients, 30 minutes included the entire treatment. Adding alfentanil to propofol resulted in obvious respiratory changes:

1. Decreased oxygen saturation compared with propofol alone during both periods; $\mathrm{p}<0.001$ and $\mathrm{p}=0.002$, respectively);

2. Reduction of respiratory rate during the first and second periods compared with propofol alone ( $\mathrm{p}<0.001$ for both periods). There were no differences in $\mathrm{SpO}_{2}$ or respiratory rate after the induction (just before the start of surgery) between the two groups when the group data were compared without taking account of changes over time;

3. Five patients became apnoeic and showed oxygen desaturation. The patients had to be manually ventilated to treat their apnoea and desaturation. Apnoea developed 
only during the first period of sedation after a period of multiple dose demands in preparation for infiltration of local anaesthesia. In three cases the procedure had not yet been started, and in the two remaining patients, the infiltration of local anaesthesia had just been completed. These five patients had lower body mass, but did not differ in age or demand:delivery ratio from the rest of the patients in the propofol/alfentanil group. They started breathing within a minute, and two of them continued to use the pump. All patients who were given only propofol breathed spontaneously during the whole procedure; and

4. Data from respiratory surveillance showed that the addition of alfentanil to propofol increased the transcutaneous and end tidal levels of carbon dioxide. All interventions to normalize data from respiratory functions took place within the first 13 minutes of sedation.

According to the BIS monitoring, patients were sedated more heavily if they used propofol alone ( $\mathrm{p}=0.04$ for $1-10$ minutes and $\mathrm{p}<0.001$ for $11-30$ minutes). Evaluation of sedation using the OAA/S scale defined five patients (the apnoeic patients) as heavily sedated as they did not respond to verbal stimuli (OAA/S level 2). All remaining patients were arousable (OAA/S levels 5 to 3 ).

Regardless of the drug/s used, cardiovascular stability was maintained throughout the period of sedation. Fifteen patients had values from systolic blood pressure measurements between 90 and $100 \mathrm{mmHg}$. One patient was treated with $5 \mathrm{mg}$ of ephedrine (systolic blood pressure $<90 \mathrm{mmHg}$ ) and with $0.5 \mathrm{mg}$ of atropine for bradycardia ( $<40$ beats/minute). This was the only case of bradycardia detected.

For 10 patients, the operation was not possible with PCS (seven given propofol and three given propofol and alfentanil), and progress was secured with additional doses of propofol given by the nurse anaesthetist. For nine of the remaining 155 patients (two in the propofol/alfentanil group) who used PCS for the whole procedure, the 
operation was done with some limitations of both view and access. For one of these 9 patients, the quality and speed of the operation were affected. Surgical time did not differ between propofol group and propofol/alfentanil group, though the addition of alfentanil influenced the ease of the operation $(\mathrm{p}=0.02)$. The treatment of incontinence and combined procedures were the most likely to fail, and were also those with more limited surgical access. For the treatment of incontinence (with TVT), patients were asked to cough or bear down while adjustment was made to the implant; one patient did not manage to cooperate and cough within a reasonable timeframe.

Doses of propofol per minute of procedure time did not differ $(\mathrm{p}=0.317) ; 6.1$ (4.1) $\mathrm{mg} / \mathrm{minute}$ for the propofol group and 5.9 (3.2) $\mathrm{mg} / \mathrm{minute}$ for the propofol/alfentanil group.

\section{Study III}

The pharmacokinetic profiles of propofol and alfentanil are shown in Figures 2 and 3. For all 155 patients, there was a short peak in the estimated $\mathrm{C}_{\mathrm{e}}$ of propofol after five minutes, and the concentration was then reduced. Alfentanil had a different profile, in that a plateau was reached after 15 minutes and the concentration was almost constant for another 15 minutes. 


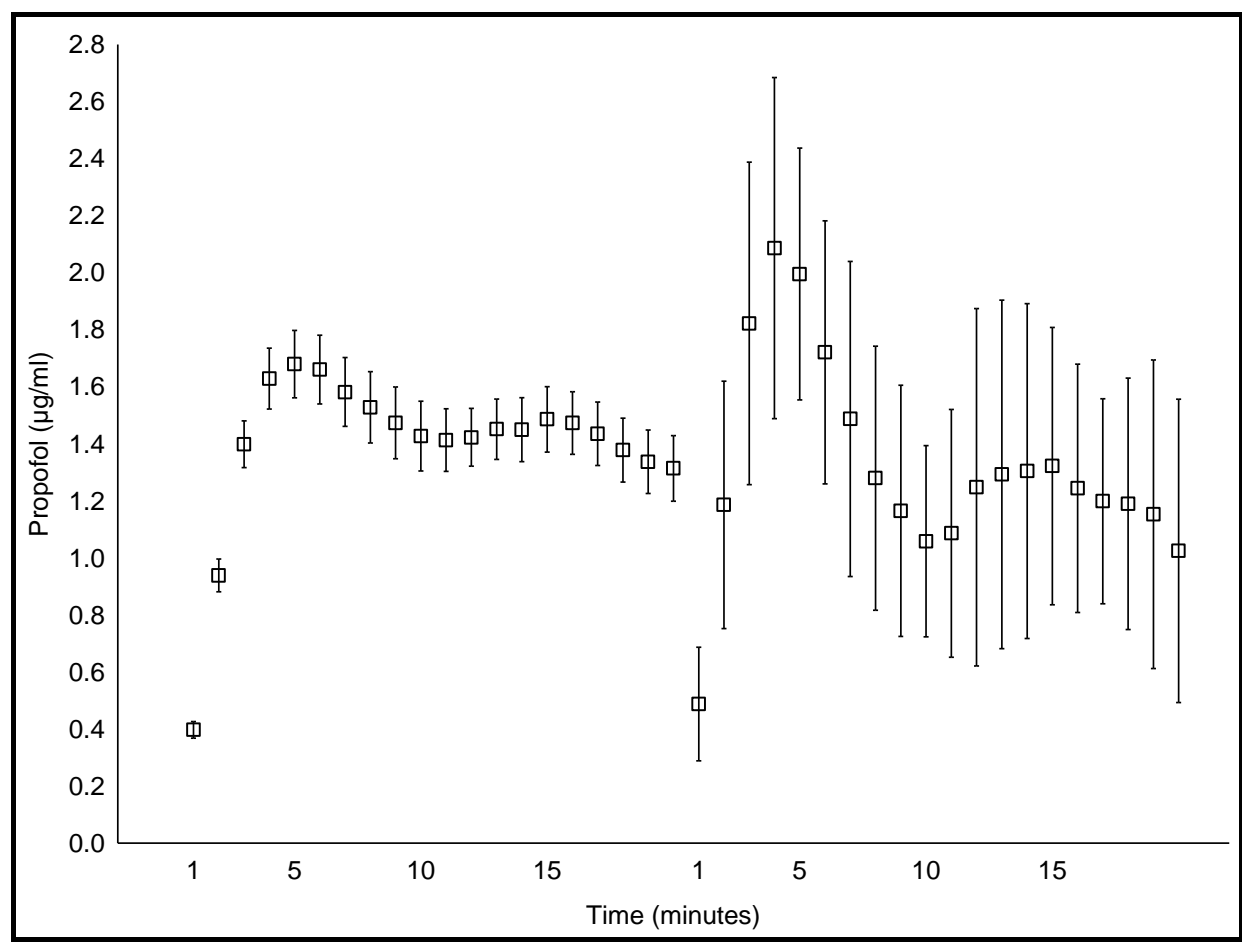

Figure 2. Estimated concentrations of propofol at effect site during 20 minutes of time comparison between all spontaneously-breathing patients given propofol $(n=145)$ and those with apnoea or obstructed airways $(n=10)$. Mean concentrations of propofol are displayed as a box and the bars indicate the $95 \%$ confidence interval (CI). The data in both graphs are from the first 20 minutes of sedation; the first half of the graph indicates the normally-breathing patients, and the second half the patients with impaired respiration. Concentrations of propofol decline further after these 20 minutes. 


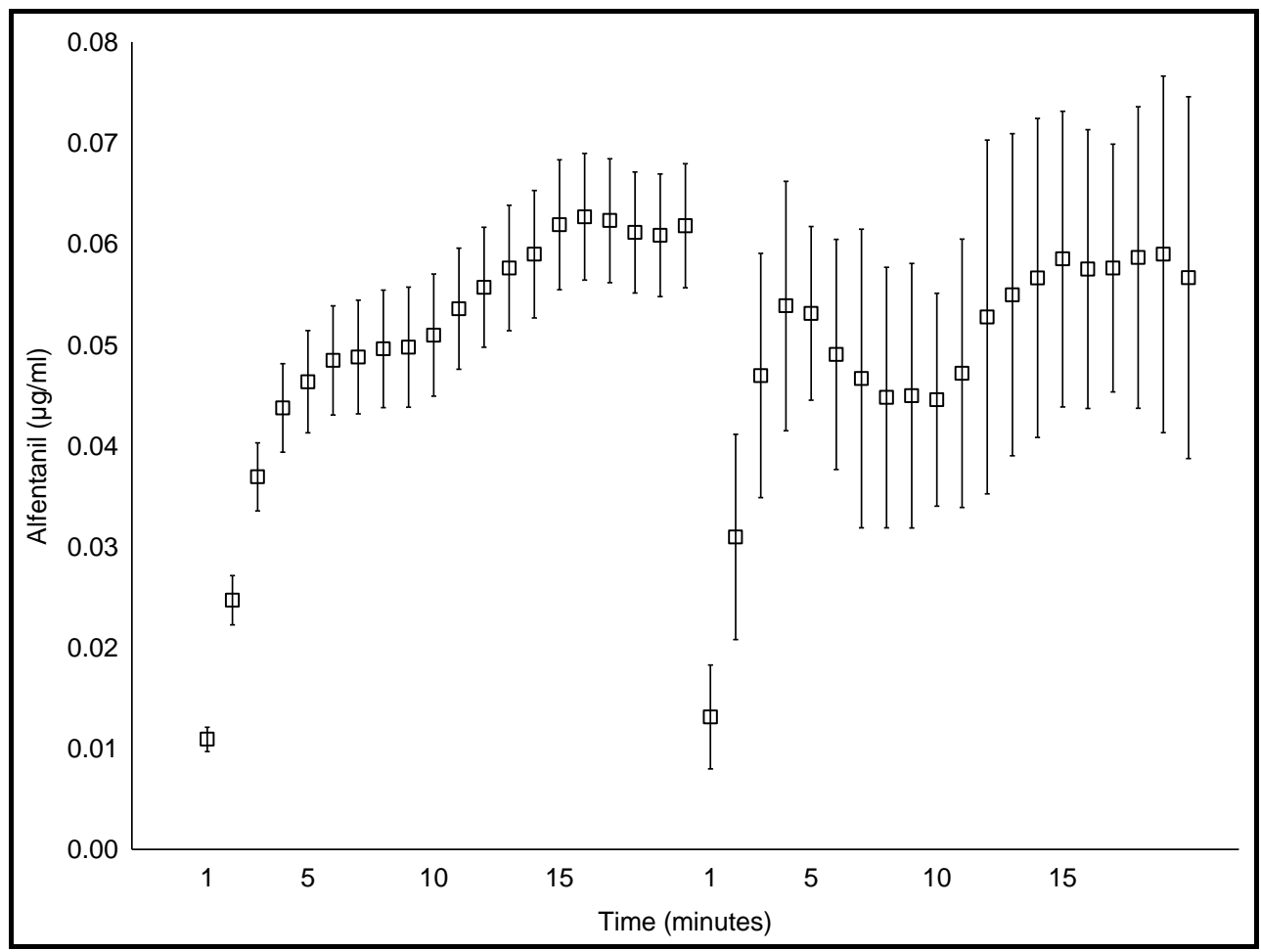

Figure 3. Comparison of the estimated mean concentrations of alfentanil under 20 minutes of time between all spontaneously-breathing patients given a mixture of alfentanil and propofol $(n=69)$ and those with apnoea or obstructed airways $(n=10)$. Mean concentrations of alfentanil are displayed with a box and the bars display the $95 \%$ CI. The data in both graphs are from the first 20 minutes of sedation; the first half of the graph indicates the normallybreathing patients, and the second half the patients with impaired respiration. The 20-minute time period represents a break-point, and the concentrations slowly decrease after this point. 
Ten of the 79 patients who had alfentanil added to propofol became respiratoryimpaired (apnoea/obstructed airway) within the first 10 minutes of sedation. ANOVA from the pharmacokinetic calculation of the $\mathrm{C}_{\mathrm{e}}$ of propofol showed no significant differences between the patients with respiratory impairment and the remaining patients in the propofol/alfentanil group $(\mathrm{p}=0.49)$; there were also no significant differences in the $\mathrm{C}_{\mathrm{e}}$ of alfentanil $(\mathrm{p}=0.40)$ patients. The only difference in characteristics between the respiratory-impaired group and the rest of the patients given alfentanil was lower weight (62 [11] kg compared with 72 [14] kg, p=0.04).

The 10 highest peak concentrations of alfentanil were not associated with respiratory events. The $C_{e}$ for those 10 patients were significantly higher than for the 10 who developed respiratory events $(0.12[0.02]$ compared with $0.08[0.01] \mu \mathrm{g} / \mathrm{ml} ; \mathrm{p}<$ 0.001). A comparison of the $\mathrm{C}_{\mathrm{e}}$ of propofol and alfentanil (Figures 2 and 3 ) indicates that the mean peak concentration of propofol in patients who developed adverse effects differed, although not significantly. The combination of propofol and alfentanil, $\mathrm{C}_{\mathrm{e}}>2.0$ and $>0.05 \mu \mathrm{g} \mathrm{ml}^{-1}$, respectively, seemed to increase the risk of respiratory events. Logistic regression also showed that the combination of $\mathrm{C}_{\mathrm{e}}$ for propofol and alfentanil contributed to the respiratory events in the 10 patients, together with age. The model explains the impaired respiratory function from the variables alfentanil $C_{e}(p=0.02)$, propofol $C_{e}(p=0.04)$, and patient's age $(p=0.03)$.

Perioperative anxiety or pain did not affect the concentrations of drugs used. Anterior repair, treatment of incontinence, and the patient's weight were associated with the concentration of propofol $\left(\mathrm{r}^{2}=0.48\right)$, which, when alfentanil was added, was not related to any of the procedures (Table 8). The addition of alfentanil was associated with a decreased concentration of propofol at the effect site, and heavier body weight influenced the increased concentration of propofol $\left(r^{2}=0.43\right)$. Heavier body weight was also associated with a significantly greater demand for doses during induction $(\mathrm{p}$ $<0.001)$. During the first five minutes, patients whose body weight was less than 80 
$\mathrm{kg}$ required a mean (SD) of 23.7 (9.1) doses, and for those who were more than 80 $\mathrm{kg}$, the requirement was 31.5 (11.1).

Table 8. Multiple regression model showing the association between details from the procedures and the patients, and the mean estimated concentrations of propofol at the effect site.

\begin{tabular}{|l|l|l|l|l|}
\hline & \multicolumn{2}{|l|}{ Propofol } & \multicolumn{2}{l|}{ Propofol and alfentanil } \\
\hline Variables & B-coef & $\mathrm{p}$ value & B-coef & $\mathrm{p}$ value \\
\hline Type of operation & & & & \\
\hline Incontinence & 0.20 & $<0.01$ & & \\
\hline Anterior repair & 0.20 & $<0.01$ & & \\
\hline Alfentanil (yes/no) & & & -0.40 & $<0.01$ \\
\hline Weight $(\mathrm{kg})$ & 0.01 & $<0.01$ & 0.01 & $<0.01$ \\
\hline
\end{tabular}

B-coef: coefficients of the independent variables. For concentration of propofol $(\mu \mathrm{g} / \mathrm{ml})$, model overall $r=0.69$; adj $\mathrm{r}^{2}=0.48$. For concentrations of propofol and alfentanil, model overall $r=0.70$; $\operatorname{adj} r^{2}=0.43$.

\section{Study IV}

In the total group of 281 patients (301 ERCP procedures), there were no serious safety events. All details of sedation and cardiorespiratory data are shown in Table 8 . Respiratory events were the most common and short episodes of oxygen desaturation were seen in all groups. Twenty-nine patients in total had episodes of semi obstructed or obstructed breathing. Most cases $(\mathrm{n}=26)$ were rated as semi obstructed (snoring) but chin lift manoeuvre was used in three patients with obstruction in group ACS. Patients developed mild hypotension (systolic blood pressure less than $90 \mathrm{mmHg}$ ) in all groups, and ephedrine was given intravenously (systolic blood pressure less than $80 \mathrm{mmHg}$ ) to two patients, one in the PCS group, and one in the ACS group.

The mean dose of propofol given for induction was similar between the ACS and PCS groups (Table 9). The mean total dose (mg) as well as the mean dose 
( $\mathrm{mg} / \mathrm{kg} /$ minute sedation time) was higher in the ACS group. Relationships between propofol doses and patients' weight for ACS and PCS are displayed in Figures 4 and 5 , and indicate that higher doses of propofol correlate to increased weight, most distinct for PCS. During ACS, we did not exceed the highest calculated infusion rate given in the protocol. All patients in the ACS group were given propofol 5-10 $\mathrm{mg} / \mathrm{kg} / \mathrm{hour}$ as induction dose for five minutes and $2-8 \mathrm{mg} / \mathrm{kg} / \mathrm{hour}$ to maintain the sedation during ERCP, or at the end of the procedure, less than $2 \mathrm{mg} / \mathrm{kg} / \mathrm{hour}$. 
Table 9. Characteristics of sedation and cardiorespiratory data for ERCP procedures. Data are number of observations, except where otherwise stated.

\begin{tabular}{|l|l|l|l|l|}
\hline & $\begin{array}{l}\text { Midazolam } \\
(\mathbf{n = 1 0 0})\end{array}$ & $\begin{array}{l}\text { PCS } \\
(\mathbf{n = 1 0 1})\end{array}$ & $\begin{array}{l}\text { ACS } \\
(\mathbf{n = 1 0 0})\end{array}$ & P value \\
\hline Failed sedation & 20 & 4 & 0 & $<0.001$ \\
\hline Ease of ERCP, Mean (SD) & $11.1(3.8)^{1}$ & $8.3(2.5)$ & $7.2(2.6)^{2}$ & $<0.001$ \\
\hline Sedation OAA/S level 2 & 2 & 4 & 39 & $<0.001$ \\
\hline Desaturation (SpO 2 < 90\%) & 4 & 2 & 10 & 0.034 \\
\hline Semi-obstructed airway (snoring) & 1 & 3 & 25 & $<0.001$ \\
\hline Hypotension & 8 & 1 & 4 & 0.038 \\
\hline Bradycardia & 0 & 1 & 0 & 1.000 \\
\hline Patients vomiting during ERCP, $\mathrm{n}$ & 2 & 4 & 1 & 0.365 \\
\hline $\begin{array}{l}\text { Mean (SD) doses of sedatives } \\
\text { (mg): }\end{array}$ & & & & \\
\hline induction dose & & $75(29)$ & $79(66)$ & 0.523 \\
\hline total dose & $4.2(1.4)$ & $236(133)$ & $337(255)$ & $<0.001$ \\
\hline mg/minute & & $6.1(3.8)$ & $7.3(3.5)$ & $<0.304$ \\
\hline mg/kg/minute & & $0.053(0.038)$ & $0.083(0.053)$ & $<0.001$ \\
\hline Duration of ERCP (minutes) & & $30(19-44)$ & $32(19-58)$ & 0.065 \\
\hline Median (IQR) & & & & \\
\hline
\end{tabular}

ACS: nurse anaesthetist-controlled sedation; ERCP: endoscopic retrograde cholangiopancreatography; PCS: patient-controlled sedation; OAA/S: Observers assessment of alertness and sedation. Desaturation $=\mathrm{SpO}_{2}<90 \%$; Hypotension $=$ systolic blood pressure $<80$ $\mathrm{mmHg}$; Bradycardia $=$ heart rate $<40$ beats $/ \mathrm{min}$

${ }^{1}$ PCS vs midazolam, $\mathrm{p}<0.001 ;{ }^{2}$ PCS vs ACS, $\mathrm{p}=0.022$ 


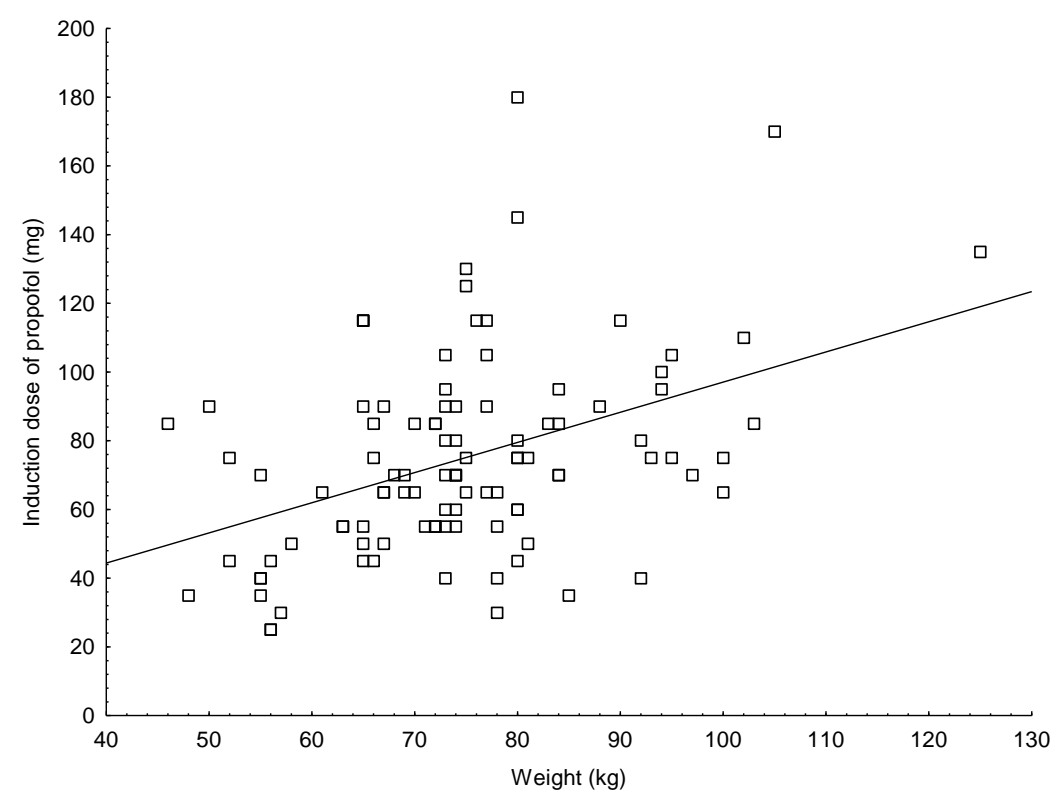

Figure 4. Relationship between induction dose of propofol and weight for PCS during ERCP. $\mathrm{r}=0.41 ; \mathrm{r}^{2}=0.17 ; \mathrm{p}<0.001$

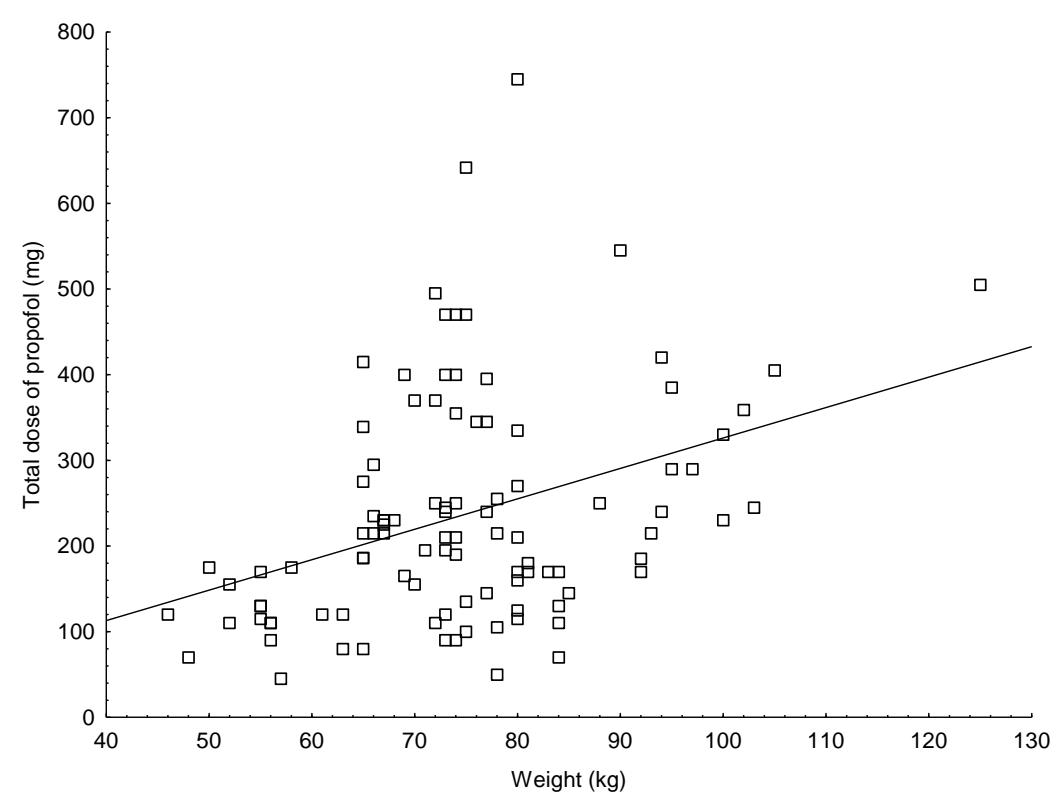

Figure 5. Relationship between total dose of propofol and weight for PCS during ERCP. $\mathrm{r}=0.37 ; \mathrm{r}^{2}=0.13 ; \mathrm{p}<0.001$ 
Ease of the procedure differed significantly between the groups, although the mean duration of the procedure did not differ. Additional doses were sometimes given in the PCS group: one patient was given two additional doses of propofol by the nurse anaesthetist, and three patients who required high doses of propofol had their sedation continued with a propofol infusion managed by the nurse anaesthetist. Twenty patients in the midazolam group had their procedures interrupted and, according to the protocol, were listed for a repeat ERCP with PCS. None of these 20 patients needed additional doses of propofol during the repeat procedure.

The period for full recovery (Aldrete score $\geq 9$ ) differed between the groups (Table 10) although the fastest speed of recovery was seen for the patients in the midazolam group, as $84 / 100$ of the patients had fully recovered by the end of ERCP (Aldrete $\geq$ 9). However, the quality of recovery differed among the groups. The intensity of pain after the procedure and incidence of sleepiness were lower for those given propofol, and within the propofol groups, the patients who used PCS rated their sleepiness lower (Table 11). 
Table 10. Mean (SD) recovery period (minutes to Aldrete $\geq 9$ ), early recovery period (minutes to Aldrete $\geq 7$ ) and number of patients fully recovered (Aldrete $\geq 9$ ) at different times after the ERCP

\begin{tabular}{|l|l|l|l|l|}
\hline & $\begin{array}{l}\text { Midazolam } \\
\mathbf{n}=\mathbf{1 0 0}\end{array}$ & $\begin{array}{l}\text { PCS } \\
\mathbf{n = 1 0 1}\end{array}$ & $\begin{array}{l}\text { ACS } \\
\mathbf{n}=\mathbf{1 0 0}\end{array}$ & p value \\
\hline Recovery period, minutes & $18(22.7)^{1}$ & $12(13.6)$ & $32(21.1)^{2}$ & $<0.001$ \\
\hline Early recovery period, minutes & $10(6.6)$ & $10(7.1)$ & $10(3.9)$ & 0.152 \\
\hline Fully recovered & & & & \\
\hline After completion of ERCP, $\mathrm{n}$ & $84^{3}$ & 63 & $29^{4}$ & $<0.001$ \\
\hline At arrival on ward, $\mathrm{n}$ & 92 & 95 & 90 & 0.565 \\
\hline 30 minutes after arrival on ward, $\mathrm{n}$ & 95 & 100 & 96 & 0.198 \\
\hline 60 minutes after arrival on ward, $\mathrm{n}$ & 100 & 101 & 100 & 1.000 \\
\hline
\end{tabular}

ACS: nurse anaesthetist-controlled sedation; ERCP: endoscopic retrograde cholangiopancreatography; PCS: patient-controlled sedation

${ }^{1}$ PCS vs midazolam, $\mathrm{p}<0.001 ;{ }^{2}$ PCS vs ACS, $\mathrm{p}<0.001$;

${ }^{3}$ PCS vs midazolam, $\mathrm{p}=0.027 ;{ }^{4}$ PCS vs ACS, $\mathrm{p}<0.001$ 
Table 11. Patients' evaluation of the perioperative ERCP procedure from a $100 \mathrm{~mm}$ visual analogic scale $(0=$ no experience of, $100=$ the most intense experience of $)$. Data are mean $(\mathrm{CI})$ or number of answers.

\begin{tabular}{|l|l|l|l|l|}
\hline & $\begin{array}{l}\text { Midazolam } \\
\mathbf{n = 1 0 0}\end{array}$ & $\begin{array}{l}\text { PCS } \\
\mathbf{n}=\mathbf{1 0 1}\end{array}$ & $\begin{array}{l}\text { ACS } \\
\mathbf{n}=\mathbf{1 0 0}\end{array}$ & p value \\
\hline Pre-procedure anxiety & $31(24-39)$ & $32(26-39)$ & $27(20-33)$ & 0.481 \\
\hline Per-procedure anxiety & $40(32-50)^{1}$ & $19(14-23)$ & $12(7-16)^{2}$ & $<0.001$ \\
\hline Per-procedure pain & $29(22-37)^{3}$ & $14(10-18)$ & $8(4-11)^{4}$ & $<0.001$ \\
\hline Post-operative & $27(20-34)^{5}$ & $15(10-21)$ & $18(12-25)^{6,7}$ & 0.032 \\
\hline \multicolumn{1}{|c|}{ Pain } & $13(8-19)$ & $7(4-11)$ & $8(4-12)$ & 0.124 \\
\hline \multicolumn{1}{|c|}{ Nausea } & $55(43-63)^{8}$ & $32(26-37)$ & $45(37-53)^{9}$ & $<0.001$ \\
\hline \multicolumn{1}{|c|}{ Sleepiness } & $65(39-72)^{10}$ & $84(79-88)$ & $90(87-93)^{11}$ & $<0.001$ \\
\hline $\begin{array}{l}\text { Overall experienced } \\
\text { procedure comfort }\end{array}$ & $50 / 12$ & $67 / 7$ & $57 / 9$ & $<0.001$ \\
\hline $\begin{array}{l}\text { Able to eat within 4 hours } \\
\text { (yes/no), }{ }^{12}\end{array}$ & $42 / 23$ & $72 / 3$ & $66 / 2^{14}$ & $<0.001$ \\
\hline $\begin{array}{l}\text { Preference for the sedation } \\
\text { if repeated ERCP (yes/no), } \\
\mathrm{n}^{13}\end{array}$ & & & & \\
\hline
\end{tabular}

ACS: nurse anaesthetist-controlled sedation; ERCP: endoscopic retrograde cholangiopancreatography; PCS: patient-controlled sedation

${ }^{1}$ PCS vs midazolam, $\mathrm{p}<0.001 ;{ }^{2}$ PCS vs ACS, $\mathrm{p}=0.21$;

${ }^{3}$ PCS vs midazolam, $\mathrm{p}<0.001 ;{ }^{4}$ PCS vs ACS, $\mathrm{p}=0.35$;

${ }^{5}$ PCS vs midazolam, $\mathrm{p}<0.001 ;{ }^{6} \mathrm{PCS}$ vs ACS, $\mathrm{p}=0.201 ;{ }^{7}$ ACS vs midazolam, $\mathrm{p}=0.21$;

${ }^{8}$ PCS vs midazolam, $\mathrm{p}<0.001 ;{ }^{9} \mathrm{PCS}$ vs ACS P $<0.04$;

${ }^{10}$ PCS vs midazolam; $\mathrm{p}<0.001 ;{ }^{11}$ PCS vs ACS $\mathrm{p}=0.19$;

${ }^{12}$ All patients were not always allowed to eat. Those who were allowed: 90/101 in the PCS group, $86 / 100$ in the midazolam group and 80/100 in the ACS group.

${ }^{13}$ This question was not always answered. ${ }^{14}$ PCS vs ACS; $p=0.731$ 


\section{Discussion}

The progress of highly efficient specialized health care demands concurrent progress in every area connected to the patients. Minor and intermediate treatments or diagnostic procedures are almost immeasurable and, in many cases, there is a need to diminish patients' experiences of discomfort, anxiety and pain. The quality of performance may also be enhanced by pain release and conscious sedation.

\section{Patients' preferences and experiences}

An earlier cross-over study addressed the preference for propofol PCS for anxiolysis instead of continuously infused propofol for dental treatment [56], while another study found that PCS for burn care received high ratings of satisfaction scores [79]. Comparable results were found in Study I of this research: all patients chose PCS for the third treatment after having tested both ACS and PCS. The cross-over design allowed for the patients to experience different aspects from the sedation and the wound treatment, and their own opinions on the benefits and drawbacks guided their choice of sedation. Regardless of the more intense pain involved with the PCS wound care procedures, the patients chose to sedate themselves during the third occasion. This robustly indicates a true preference for PCS, even in painful situations. High ratings of satisfaction may not always give information on true preferences or quality of sedation experienced by the patients. It can be troublesome to evaluate data if the patients are equally satisfied or if sedation has provoked amnesia. The clinical importance of small differences measured by the use of visual analogic scales can also be questioned. In Study IV, the differences experienced in overall procedure comfort between the midazolam and PCS groups was distinct, and most reasonably, clinically important. The preference for PCS sedation, if repeated ERCP was necessary, was not significantly different in comparison to ACS. Several of the 
measured aspects of experiences from sedation and ERCP may be the reason for this choice: less perceived per-procedure pain and anxiety, less post-operative pain and sleepiness. In Study I, the patients chose PCS despite higher pain scores. Patients appreciated being less drowsy post-procedure, and chose PCS despite the pain. Since propofol and midazolam have no analgesic effects, the finding of differences in postoperative pain after ERCP is interesting. A possible explanation is that patients express less muscle defence and movements when being intubated (oesophageal) and during the positioning of the endoscope, when propofol is used. In most of the cases, failed sedations were caused by movements and a decreased ability to cooperate, and those cases of ERCP that were finished with the use of midazolam were still rated as more difficult to perform. The most prominent differences between PCS and ACS were expected due to the difference in propofol consumption: all ERCP procedures were completed successfully and the patients rated themselves to be slightly sleepier post-operative (no differences between ACS and midazolam).

Propofol PCS has not been shown to be superior to placebo PCS regarding patient's satisfaction for cerebral angiography [80]. According to the authors, the result emphasizes the placebo effect and the importance of continuously giving information and explanations from the attending anaesthesiologist. One could also presume that the anaesthesiologist's attention and the information given to the patients slightly changed whether or not the patients received propofol; interfering bias could be expected. Although interesting, it does not shed any light on the patients' preference for PCS over ACS in the present study.

The cross-over design used in Study I made the patients their own control group. The most accurate way of cross-over would have been to randomize between PCS and ACS for the first procedure. That randomization was not chosen as it was considered to expose the patients to unnecessary risks of severe pain. For example, the first wound dressing after surgery is understood to strain the patients more than the 
second. Selection bias may have influenced the ratings of pain and the differences between the doses of drugs. Patients were given larger amounts of drugs and were more heavily sedated during ACS, which could display unnecessarily deep sedation. Amnesia from the procedures may affect patients' evaluation of any peroperative aspects, not only pain evaluation. In addition, the patients used the PCS system differently; some of the patients were almost awake and some were more sedated. Recorded doses of drugs are considered to have the same effect on memory for the PCS and ACS groups. The differences between the groups indicate that the patients had an opinion on the quality of the sedation. Questions on the perioperative experiences cover more than the peroperative quality and give a general evaluation of the procedures from the patients. The questionnaires were distributed when the patients were awake and were to be completed within two hours after the end of the procedures. Memories of experiences of pain or anxiety may fade after some hours and prompt completion within two hours was thought to support the best accuracy.

The questionnaire used in Study I was also used in Studies II-IV, although some questions were added. The planning for Study II involved pilot studies whereby the questionnaires were distributed and adjustments made according to comments or missing data. Visual analogue scales were used for data on postoperative nausea, pain (Study II-IV), and tiredness, and the patients' overall comfort during the procedure (Study IV). Many patients are familiar with VAS and it is easily taught to complete the questionnaire. Although VAS evaluation of anxiety, pain and nausea is common, valid and useful [81], VAS may not include aspects of anxiety measured by specific measurements, such as the Beck Anxiety Inventory scores or the Spielberger's StateTrait Anxiety Inventory. Coping strategies may also influence patients' behaviour and the number of requests for sedatives. This aspect was not evaluated in the present study. 


\section{Cardiorespiratory functions and interventions}

PCS has been evaluated as safe [37] or as representing a decreased risk for oversedation and cardiorespiratory events compared with ACS [50,82]. This is not yet supported by any large review articles or Cochrane analysis. Several issues influence aspects of safety for the use of PCS.

The major objection to statements of perceived safety are the limited number of patients included in PCS studies in general. In many cases, less than 100 patients are included. One of the largest studies included 500 patients scheduled for colonoscopy [37] and used propofol $(4.8 \mathrm{mg})$ and alfentanil $(0.12 \mu \mathrm{g})$ boluses without lock-out periods. Incidence of hypotension (systolic blood pressure $<90 \mathrm{mmHg}$ ) was $8.6 \%$, of which some patients received fluid treatment. Supplemental oxygen was given to all patients and no incidences of oxygen desaturation or apnoea were recorded. In comparison, Studies I-IV included 457 patients who used PCS in three different situations, resulting in five apnoeic patients. Incidences of respiratory events (1\%) stress the need for a setting where accurate interventions can be performed and the need for tuning the PCS system for every clinical situation. The use of PCS in the burn setting (Study I) was considered to provide safe conditions for the patients, most likely because of insufficient pain treatment involved with the wound treatment. All patients using PCS responded to verbal stimuli and the doses of propofol delivered were half those given during ACS. Also, complementary oxygen was delivered. Although the concentration of alfentanil was higher than reported previously (at that time), patients in burn care are usually in need of high doses of opioids for pain release. It was unlikely that any adverse reactions would have occurred. Also, some of the patients displayed a high ratio of demanded-delivered doses and were not satisfied with the capacity of the pump. The patients' expressed intensity of pain indicates inadequate pain control from the PCS system. 
Almost the same doses of the drugs were used in Study II as in Study I. Supplementary oxygen was not given from the start and the pain from surgery was controlled by local infiltration. Mild respiratory impairment and the need for supplemental oxygen were expected in some of the cases, as reported previously, with only propofol (healthy volunteers) [83] and propofol/remifentanil (colonoscopy) [51]. Although some respiratory impairment was expected, apnoea in five cases was not. Sedation for ERCP has been evaluated from the use of propofol/alfentanil PCS (propofol $8 \mathrm{mg}$ and alfentanil 0.04 or $0.08 \mathrm{mg}$ per dose demand), also resulting in respiratory depression [84]. These doses of alfentanil are nearly twice as large compared to Study II and the risk for respiratory depression must have been expected. Although the addition of alfentanil (transvaginal ultrasound-guided oocyte retrieval) [54] and remifentanil (breast biopsy procedure) [49] to propofol have been reported not to cause respiratory depression, the mixture of propofol and opioids are troublesome. In highly demanding situations (Study I), the addition of an opioid is essential due to severe pain and tachyphylaxia. The same PCS model in a different setting may lead to serious events. It is obvious that the aggressiveness of the PCS model must be adjusted for each procedure. The addition of a third component for pain control (local anaesthetics) makes the outcome even more complex. Stimuli involved in the procedures are most certainly crucial for the safety of PCS. The PCS system must be perfectly matched to the demands for pain and anxiety control. Endoscopic procedures involve constant stress for patients, or even increased pain intensity, and doses of propofol and opioids could be larger than the doses used for procedures involving local anaesthesia, where the pain or discomfort may be present only at the start when the infiltration or blocks are given. Given the information from Studies II and III, it is considered safer to use propofol alone.

If induction prior to the infiltration of local anaesthesia could be ensured from the use of propofol PCS and the pain could be prevented by a small bolus of an opioid before PCS starts, conditions for safety would probably be enhanced. This assumption may 
be supported from the information in Study III, Figures 2 and 3. The $\mathrm{C}_{\mathrm{e}}$ of propofol rises rapidly to a maximum within five minutes, and then the concentration declines. This includes both the normally breathing and the respiratory-impaired patients. According to Figure 3, alfentanil $\mathrm{C}_{\mathrm{e}}$ also increases rapidly but instead of subsequently decreasing, the concentration remains high or even increases after 10 minutes when the patients start to make dose demands again. Together, these rapidly increased concentrations of drugs result in apnoea or airway obstruction. Concentrations of propofol, with or without opioids, and the relationship to the loss of consciousness (LOC) have been examined for un-premedicated patients. LOC according to the OAA/S (conscious = OAA/S level 5-3) for propofol $\mathrm{C}_{\mathrm{e}}$ have been calculated to 2.2$2.5 \mu \mathrm{g} / \mathrm{ml}(\mathrm{CI} 95 \%)$ without opioids. When alfentanil $\mathrm{C}_{\mathrm{e}}$ of $0.1 \mu \mathrm{g} / \mathrm{ml}$ was reached before the start of infusion of propofol, propofol $\mathrm{C}_{\mathrm{e}}$ decreased to $1.5-1.8 \mu \mathrm{g} / \mathrm{ml}$ [85]. These levels are similar to the findings in Study III: apnoea/obstruction was induced at CI 95\% 1.5-2.7 $\mu \mathrm{g} / \mathrm{ml}$ for propofol. Although mean alfentanil $\mathrm{C}_{\mathrm{e}}$ was lower in Study III $(0.06 \mu \mathrm{g} / \mathrm{ml}$, compared to $0.1 \mu \mathrm{g} / \mathrm{ml})$, the propofol $\mathrm{C}_{\mathrm{e}}$ were more widely spread in our data. In Study III, no late respiratory depressions were recorded, most probably because of the declined propofol $\mathrm{C}_{\mathrm{e}}$. However, theoretically, after 20 minutes the calculated alfentanil $\mathrm{C}_{\mathrm{e}}$ was still high, and multiple dose demands could easily increase the propofol $\mathrm{C}_{\mathrm{e}}$ and lead to unconsciousness/apnoea. Also, data from mixed-effects modelling suggest that propofol and alfentanil interact, which alters the precision of the simulation of effect site concentrations. Alfentanil has been shown to decrease elimination clearance and distribution clearance of propofol [86], while propofol decreases the elimination clearance and distribution clearance of alfentanil [87]. The data in Study III display the problem of having two drugs in the same syringe, which is the onset of the drugs too rapidly at induction (respiratory impairment) and the risk for late respiratory depression since the concentration of alfentanil remains high for the first 20 minutes. PCS with propofol could be improved by giving opioids manually (decreasing the dosage of opioids at a certain age) or by adding pharmacokinetic calculation software into two PCS devices, one for each 
drug. Injections of small doses of opioids beside the propofol PCS seem to enhance aspects of safety.

In Studies II and IV, predefined limits for the cardiorespiratory surveillance were used. The limits for blood pressure, heart rate and respiratory rate and the interventions performed are similar to earlier surveys [49, 88]. Interventions made in Studies II and IV indicate that sedation must be continuously supervised in order to restore physical changes. Study II examined the expected side-effects from the combination of propofol and alfentanil: apnoea, oxygen desaturation, increased levels of $\mathrm{CO}_{2}$, need for oxygen, chin lift and mask ventilation. The addition of alfentanil increased the need for interventions/resuscitation. According to Study IV, occasions of desaturations, hypotension and deep sedation (OAA/S level 2) is overrepresented during ACS, which is similar to meta-analysis on propofol sedation for endoscopies $[59,89]$.

Peroperative monitoring of pulse oximetry, non-invasive blood pressure measurements, ECG, respiratory rate, and end-tidal carbon dioxide (IntelliVue MP30 Philips Healthcare, Best, the Netherlands) is used on a daily basis worldwide. However, the measurement of transcutaneous carbon dioxide is not, and must be discussed. With decreasing blood pressure and dermal perfusion, the accuracy is supposed to be impaired, and in those cases, the data from tissue will not mirror the actual central values of carbon dioxide. However, since PCS has been described as contributing only to a minor decrease in cardiovascular function $[37,90]$ and since an up-going trend in carbon dioxide was of main interest rather than absolute values, the transcutaneous measurement was considered suitable. With increasing age, the more keratinised the dermis becomes, and the greater the gradient becomes between arterial and transcutaneous measured levels of oxygen. On the other hand, $\mathrm{CO}_{2}$ is highly soluble and age does not have that high of an impact on reliability; thus, with correct placement of the sensor, $\mathrm{P}_{\mathrm{tc}} \mathrm{CO}_{2}$, collected with TCM3-TINA, the monitoring 
has been held as accurate [91-94]. This regimen for surveillance provides cardiovascular data together with data on respiration and oxygenation. Co-variance of impaired data in the patient's vital functions was of most interest and could point at over-sedation and an increased risk for serious events.

Oxygen delivery from the start may hide the impaired effects sedation has on respiration and oxygenation. In Study II, a decrease in oxygen saturation $\left(\mathrm{SpO}_{2}<\right.$ 90\%) determined the delivery of oxygen. Using this strategy, the influence of propofol and the addition of alfentanil could be more clearly explored. Interactions from the nurse anaesthetist (encourage the patient to breathe, give oxygen, moderate patient's airway, and mask ventilation), together with the extended surveillance of respiratory values and trends, reveal safety issues in a more detailed manner. The use of a flow of air from the start and the switch to oxygen if needed provided equal circumstances for the sampling of $\mathrm{CO}_{2}$ and the measurement of respiratory rate. Data on $\mathrm{CO}_{2}$ and respiratory rate were used as trends rather than absolute values because of possible sources of error (patients talking was one of the most influential factors). In Study IV, oxygen was increased if $\mathrm{SpO}_{2}$ went below 90\%. The administration of oxygen through nasal catheters for the ERCP patient presumably reduced the $\mathrm{FiO}_{2}$ because of the endoscope and a higher oxygen flow was chosen.

Baseline values and the intervals of three or five minutes were considered to be enough to record and statistically secure differences between groups. Most of the surveillance was monitored continuously and obvious changes were documented inbetween the intervals. The pre-set limits guided the nurse anaesthetist to intervene uniformly for any impaired vital signs, and the limits chosen were clinically relevant and correspond to the usually defined limits in sedation research. Extra doses of propofol given by the nurse anaesthetist if needed were thought to provide short episodes of deeper sedation. Sedation was planned to be maintained from PCS only. 
If the demand for sedation exceeded what was possible through the PCS system, multiple doses or an infusion of propofol was initiated by the nurse anaesthetist.

Conclusively, adding opioids to a propofol PCS model increases the patients' risks, if reduction of pain is controlled by a third component, and the risk for episodes of break-through pain or background pain is small.

\section{Level of sedation and patients' use of PCS}

In Study I, all PCS patients' responded to verbal commands, as the patients who were given only propofol in Study II did. Study I displayed BIS levels corresponding to minimal to moderate sedation. Mean BIS levels over procedure time in Study II indicate heavier sedation in the patients who were given propofol only. All patients responded to verbal commands (OAA/S level 5-3), except five in the propofolalfentanil group (OAA/S level 2). Usage of propofol alone results in larger doses required compared to sedation for endoscopic procedures titrated with combinations of propofol and opioids [95, 96]. This is also demonstrated in Study II. In Study II, BIS indexes indicate signs of amnesia, as a lack of recall for a majority of healthy volunteers occurs at BIS values of 77 [71]. According to the same study, failure to respond to verbal commands for $50 \%$ of the patients matches a propofol plasma concentration of $2.35 \mu \mathrm{g} / \mathrm{ml}$. Comparable data on propofol $\mathrm{C}_{\mathrm{e}}$ are also reported [85]. Study IV had four episodes of deeper sedation (OAA/S level 2) for those who had a larger need of sedation than that offered from the PCS system. These episodes were short and a result of the nurse anaesthetist's additional sedation. In most of the cases in Studies I-IV, the sedation was considered to be minimal to moderate and purposeful.

The BIS index and the OAA/S scale were used for the detection of episodes of deep sedation. Since the indexes relating to over-sedation were of primary interest, the 
patients' talking and movements that caused measurement interference did not lower the level of validity and reliability. The procedures in Studies I and II did not intervene with an accurate electrode placement. The OAA/S scale is easy to use, gives rapid information and the interaction with the patients during procedural sedation is natural from the anaesthetist's point of view. OAA/S has been used in other studies on sedation enabling the comparison of data.

Study III did not reveal any correlations between the patients' evaluation of perioperative anxiety or pain and the calculated propofol $C_{e}$. The same has been reported on sedation for colonoscopy [97]. The opposite is stated when moderate sedation from target-controlled infusion (TCI) supports oocyte retrieval: the higher the anxiety, the larger the doses of propofol needed [98]. In Study IV, doses of propofol and patients' weights plotted in Figures 4 and 5 reveal some correlation. The opposite is reported: no linear correlation between weight and delivered doses of propofol [83]. However, when only propofol was used, propofol $\mathrm{C}_{\mathrm{e}}$ in Study III was associated with the patient's weight and two of the gynaecological procedures (treatment for incontinence and anterior repair). When alfentanil was added to propofol, propofol $\mathrm{C}_{\mathrm{e}}$ was decreased by the addition of alfentanil and increased with weight. According to the pharmacokinetic formula, the influence of weight should have been already calculated for. The influence of weight that was found could be explained by the fact that Schnider's PK model was developed in normal-weighted individuals and the central volume is not proportional to weight. Mean weight for the 11 females in Schnider's original paper [76] was $69 \mathrm{~kg}$ (range 44 to $91 \mathrm{~kg}$ ). In Study III, the impact on the regression analysis from the nine patients between 102 and 121 $\mathrm{kg}$ of weight could be enough to explain the impact of weight on propofol $\mathrm{C}_{\mathrm{e}}$. From a clinical perspective on the use of PCS, increased weight intensifies the dose demands from patients, presumably explained by the lower effect from the doses. The feedback within the individual from each dose leads to more intense dose demands in comparison to patients of less weight. 
The pharmacokinetic simulation in Study III was based on the pharmacokinetic models described by Schnider et al. [76, 77] and the profiles of alfentanil were simulated from the model described by Scott et al. [78]. The present simulation shows that a mixture of two drugs with different pharmacokinetic profiles in the same syringe might compromise safety (occasions of deep sedation), also reported earlier $[84,99]$. To my knowledge, pharmacokinetic simulation has rarely been used for PCS studies. Although differences exist between simulated and measured concentrations, and different timeframes for target concentrations [100, 101], and the individual clinical response to a specific $\mathrm{C}_{\mathrm{e}}$ is hard to predict, patient's adjustments of sedation using target-controlled propofol infusion have supported dental treatment $[102,103]$ and colonoscopy[104]. Inclusion of a clinical observation approach to

control the loss of consciousness may reduce the impact of biological variability if TCI of propofol is used [105], but its use with TCI or PCS in clinical practice is unclear. The evidence of age as an explanatory variable is confirmed. Use of TCI anaesthesia has shown that age affects the association between the $\mathrm{C}_{\mathrm{e}}$ of propofol and the loss of, and return to, consciousness [106].

\section{Procedure characteristics and recovery}

Study II indicated that the addition of alfentanil influenced the ease of the operations. The surgeons assessed some limitations of view and access when patients used only propofol for PCS, although procedure time was unaffected between the groups. PCS has been rated as effective (procedure time) when compared to endoscopist-directed sedation from benzodiazepines during colonoscopy [107] and compared to propofol infusion directed by anaesthetists [108].

Randomized use of PCS for ERCP using propofol $(8.0 \mathrm{mg} / \mathrm{ml})$ together with alfentanil $(0.04 \mathrm{mg} / \mathrm{ml}$ or $0.08 \mathrm{mg} / \mathrm{ml})$ or remifentanil $(0.01 \mathrm{mg} / \mathrm{ml})$ and $1 \mathrm{ml}$ as a 
bolus, evaluated the addition of alfentanil to provide less incidence of failed sedation and converted sedations, and high endoscopist satisfaction [84]. The addition of remifentanil was also associated with an increased risk of respiratory depression $(33 \%)$, oxygen desaturation $(26 \%)$ and nausea $(22 \%)$. Procedure time for the three groups was not affected by the choice of drugs. This supports the results in Study II. However, compared to Study IV, the data on failed sedations or converted sedations did not seem to differ, despite the addition of alfentanil in the ERCP study. The total incidence of converted sedations (repeated doses of propofol given by an anaesthesiologist) was $4 \%$ in the alfentanil groups, and failed sedations (sedations converted and safety interventions performed) had an incidence of $7 \%$ in each alfentanil group. In Study IV, the incidence of PCS converted to ACS was 4\%. Most probably, a lot of details concerning information, expectations, personnel's professionalism, etc., contribute to the overall acceptance of the procedure and the success rate. Patients' preference for PCS must also be considered; the results in Study I are confirmed in another cross-over study of dental phobic patients who strongly preferred PCS instead of clinician-controlled propofol sedation [63]. In Study IV, patients from the midazolam group were transferred to the PCS group, if the ERCP had to be interrupted due to sedation insufficiency. All of these 20 patients completed the ERCP using PCS. The data would probably differ slightly if alfentanil had been added, and a slightly increased acceptance for the ERCP procedure could be expected. PCS seems not to prolong the procedure time, as indicated in Study IV.

Study IV indicates a rapid recovery after PCS guided from the use of the Aldrete score. The number of fully recovered patients immediately after finishing ERCP differed between the groups: $84 \%$ for the midazolam group, $63 \%$ for PCS and $29 \%$ for ACS. In a comparison of minutes to full recovery, PCS seems to be the most rapid, most probably because of the rapid clearance of propofol from the central compartments and from the lower amount of propofol given. A rapid recovery from PCS and the lower amounts of propofol administered compared to ACS [90] and TCI 
[48] have been previously reported. One exception is PCS and ACS using propofol and one pre-set injection of fentanyl according to weight for minor surgical and anaesthetic procedures [109]. Those authors report higher doses of propofol used in the PCS group and a higher risk of unwanted sedation at the end of the procedure and arrival at the recovery area. Anaesthetists' limited knowledge about the characteristics of the procedure is stated as one of the reasons for the differences in doses given by the end of the procedure. This suggests that continuous interaction with the patient and surgeon is crucial for optimal adaptation to the procedures.

The incidence of post-operative pain, nausea and sleepiness differed between the groups, with the PCS group experiencing these problems the least. Post-operative recovery and quality are influenced from the sedation and the drugs used and also from the procedure performed. ERCP is associated with experiences of discomfort and pain, peri- and post-operative, due to the gut distension. Insufflation with carbon dioxide instead of air can reduce post-operative pain but does not affect the recovery time [110]. In Study IV, air was used.

The feasibility and quality of the procedures was assessed from data on conditions for performing the treatment. Different pre-, peri- and post-operative periods were registered in minutes, providing hard data on the situations for the procedure performed (Studies I, II and IV). In Study II, the surgeons estimated the adequacy of access and visibility using a four-point scale, and in Study IV the endoscopists evaluated the ease of the ERCP procedure using a structured questionnaire [40] covering six aspects of ERCP performance. The surgeons in both studies discussed the scale and the instrument to agree on how to interpret the different steps. The ERCP instrument was used as it is published in [40]. The measurements were chosen to mirror useful information prior to clinical implementation of PCS. The Aldrete score [75] used in Study IV aided the recording of different time periods of early recovery. The Aldrete score may be considered less detailed compared to the poly- 
dimensional measurement of recovery from the Post-anesthesia Recovery Score for Ambulatory Patients (PARSAP) [111] or the Post-discharge Surgical Recovery scale (PSR) [112]. In the future, PSR could be used for the collection of complementary data for enhanced and deepened understanding. The focus of the thesis was primarily to assess the possibility of implementing sedation from PCS instead of ACS.

\section{General limitations}

The included studies cover three important areas of PCS: safety issues, performance of procedures and patients' experiences. The number of included patients is too small for a safety analysis in terms of morbidity/mortality outcome. Instead, specific changes in vital functions and the interventions made could support a clinical implementation of PCS for procedural sedation, and the decision of the competence needed to be responsible for the sedation. Studies of less than 500 patients did find specific limitations in aspects concerning safety that could bring into question the widespread use of PCS. The single-centred approach could make the results of performance difficult to generalize. A multi-centred approach was planned for Study IV, but was not chosen because of the different routines for sedation and treatment existing in the hospitals, thus making it hard to establish and difficult to evaluate. The validity of the presented results is strengthened by a high compliance to the protocols. Communicating within the research teams was easy due to the low number of individuals collecting data, performing procedures and overseeing the procedures. Well-known scales, devices and techniques for recording data were chosen from a perspective of high validation, ease-of-use and comparability between the studies. The low number of patients in Study I was to some extent compensated by the crossover design. Interviews with the patients could have deepened the understanding of the benefits of PCS compared to ACS. However, the clear preference for PCS was considered enough to proceed and evaluate PCS in further studies. When possible, the studies are double-blind (Studies II and III) and the results were used for the 
protocol of Study IV. The use of detailed protocols and CRF have supported conformity in the interventions made and the data collection, and have very likely contributed to minimizing the bias from unilateral decisions (pre-set limits for vital signs and the interventions needed).

\section{Clinical importance and future research}

An ongoing debate includes how we sedate the patients, what sedatives and doses we use and who should be responsible for the procedural sedations. This thesis can be used for guidance to implement a PCS model into the clinical situation, but may also guide further detailed work.

Induction at the start of each procedure was not controlled in Studies I, II and IV; the patients were free to induce themselves to tiredness, and at that point, the procedure started. In Study II, the PCS model was too aggressive; hence, severe respiratory impairment occurred in the opioid group. The feedback that the patient gets from the system is most certainly of great importance for the acceptance of self-control and to experience that the system works. In other studies, doses for induction were calculated by weight and given to the patients by personnel before the procedures, in order to induce and start the procedure rapidly. Since time periods for the procedures in Studies I and IV were unaffected, this argument is not of significance; however, the feedback mechanism seems important for the patients. Future surveys could evaluate the importance and effect from the initial feedback.

Could PCS using only propofol provide the conditions required for demanding procedures and support the patient's comfort? Study IV supports this. ERCP can be performed using propofol PCS, and data indicate almost the same conditions for ERCP performances as compared to moderate sedation given by nurse anaesthetists. Performance may be even easier if an opioid was given at the time for oesophageal 
intubation, and depending on the dose, this could most probably be done with a minor increased risk of respiratory depression.

Can the outcome of PCS use be predicted from data concerning the type of surgery, the patient's demographics or from the patient's evaluation of pre-procedural anxiety? The results from Study III do not seem to support this. The regression model indicates instead that the patient's weight and the type of procedure influence the concentrations at the effect site. Since the propofol $\mathrm{C}_{\mathrm{e}}$ is calculated from the patient's weight, heavier patients seem to demand larger doses of propofol or express a more aggressive use of the PCS pump. The feedback they get from the fixed boluses may be less obvious compared to the feedback of a thinner patient. This could to some extent explain the differences in $\mathrm{C}_{\mathrm{e}}$. Programming of different bolus doses by weight could enhance the PCS pump's performance. The effects on safety and efficiency from such programming could be easily evaluated in a randomized study.

Every procedure is unique when it comes to patients and their experienced levels of anxiety and pain. If pain cannot be treated without the use of opioids, they have to be used. If anxiety and discomfort are the limiting issues, propofol PCS without the addition of opioids is recommended. PCS use as an adjunct to local anaesthesia and regional or central blocks could be easily adjusted to particular needs. As PCS supports indifferent procedure time when compared to different techniques for sedation, and as PCS results in rapid recovery, there is a margin for the addition of single doses of opioids if needed, or a short break to let the patients sedate themselves to a suitable level.

Could PCS be used by nurses and doctors not specialized in anaesthetics? To aid safe propofol sedation managed by non-anaesthetists, guidelines for procedural sedation have been compiled by the "Svensk förening för anestesi och intensivvård (SFAI)" [113]. PCS could further aid requests for sedation performed outside the traditional 
anesthesia theatre regarding safety and effectiveness. Fewer doses of propofol, generally good conditions for treatments or diagnostic procedures, and patients' preferences are in concordance with SFAI's recommendations. However, depending on the procedure, the drugs needed (addition of opioids) and the support from and collaboration with the anaesthesia department, PCS may contribute to a transfer of procedures from anaesthesia theatres to office-based facilities. Securing the patients' safety and development of a suitable regimen for the PCS system must include a genuine interest from the procedure personnel. PCS may also require slight revisions in routines, behaviour and care so that patients are able to communicate and be a part of the procedure in an enhanced manner. 


\section{Conclusions}

\section{Study I}

PCS was preferred by the patients despite being given less sedatives and their evaluation of more pain. The patients preferred PCS because they had better control and there was less post-procedure sedation. PCS using propofol and alfentanil appears to be an interesting alternative to ACS for dressing changes in minor to intermediate burns. PCS had a low impact on patients' cardiorespiratory functions and supports minimal sedation during treatments; ACS resulted in occasions of deep sedation.

\section{Study II}

PCS using propofol alone seems to be the safest alternative for providing sedation during gynaecological procedures. The addition of alfentanil reduced respiratory rates, decreased oxygen saturation, and resulted in some patients not responding to verbal stimuli and becoming apnoeic. Cardiovascular stability was maintained without any difference between the groups. The addition of alfentanil positively influenced the ease of the operation, although operating time was unaffected. Ten out of 165 patients had to be given additional propofol beside PCS to continue surgery. Eight were given PCS with propofol only.

\section{Study III}

According to the pharmacokinetic simulation, the profiles between propofol and alfentanil differed. Concentration of propofol at the effect site peaked within five minutes and then slowly declined. Concentration of alfentanil increased slowly and 
reached a plateau after 15 minutes, remaining constant for at least 20 minutes. The type of surgical intervention and the patient's weight were associated with the concentrations of propofol at the effect site. When alfentanil was added to propofol, no association with the type of surgery remained; instead, alfentanil and the patients' weight explained the concentration. Self-rated pre- or peroperative anxiety or perioperative pain did not affect the effect site concentrations.

\section{Study IV}

PCS with propofol is superior to midazolam and comparable to propofol sedation handled by nurse anaesthetists for ERCP procedures. PCS results in rapid recovery with a low incidence of nausea, pain and sense of sleepiness. PCS requires few safety interventions during sedation and almost all patients respond verbally during the procedures. PCS is almost as effective at easing the ERCP procedure as ACS despite less propofol being administered. Four of 100 ERCP procedures using PCS were completed by additional sedation given by the nurse anaesthetist. The duration of ERCP did not differ between the groups.

\section{General conclusions}

PCS seems to be preferred by patients even if the circumstances are quite demanding and include discomfort and pain. PCS can be adjusted to cover a broad range of areas in which sedation is needed. Burn wound treatment most certainly demands the addition of opioids, before and during the procedure. PCS as an adjunct to surgical procedures also using local anesthesia could be performed without the addition of opioids, even if adding alfentanil increased the surgeons' access to the patients. For the discomfort and pain involved with endoscopic procedures, propofol PCS performs almost the same as when anaesthetists perform sedation. Overall, regarding the pre-operative procedures, PCS does not seem to be time-consuming. With respect 
to the perioperative perspective, PCS supports rapid recovery with a low incidence of tiredness, pain and PONV.

The data further suggest that PCS must be adapted to the patient, the specific procedure and the circumstances for the sedation. PCS using propofol only gives minimal to moderate circulatory changes and a sedation level where the patient responds to verbal commands. The addition of alfentanil poses an increased risk for apnoea and oxygen desaturation and enhanced readiness for specific interventions. 


\section{Summary in Swedish}

Behovet av sedering för undersökningar och kortare behandlingar inom sjukvården är omfattande och ökande. Kortare behandlingar eller diagnostiska procedurer utförs idag med otillräcklig sedering eller utan sederande eller smärtlindrande läkemedel. Tillvägagångsätt och rutiner för sedering vid avancerade högkvalitativa vårdtillfällen som samtidigt ger en snabb återhämtning efterfrågas för ökad effektivitet. I denna doktorsavhandling studerades patientkontrollerad sedering (PCS) med propofol och alfentanil vid kirurgiska och diagnostiska ingrepp. Det övergripande syftet var att studera aspekter av säkerhet, procedurernas genomförbarhet och patientens upplevelser. Hypotesen var att PCS med enbart propofol är en säker och effektiv metod för att inducera och underhålla till en måttlig sederingsnivå. De inkluderade studierna var prospektiva interventionsstudier som i vissa fall även var randomiserade och dubbelblindade. Data rörande förändringar i hjärt- och andningsfunktioner, sederingsgrad, peri-operativ smärta, obehag, oro, illamående, interventioner som utförts av anestesisjuksköterskor, kirurgernas utvärdering om procedurens genomförbarhet, återhämtning (Aldrete poäng) och farmakokinetiska simuleringar av läkemedelskoncentrationer låg till grund för analys och jämförelse mellan PCS och narkossköterske-/narkosläkarstyrd sedering samt mellan PCS med enbart propofol och PCS med en kombination av propofol och alfentanil.

Resultatet visar att PCS kan anpassas för att fungera inom skiftande områden där sedering behövs - brännskadevård, gynekologisk öppenvårdskirurgi och endoskopiska procedurer för diagnostik och behandling av sjukdomar i gallgångarna (ERCP). PCS för sårvård vid brännskadebehandling kräver högst troligt tillägg av alfentanil. PCS föredrogs av patienterna framför sedering given av narkosläkare. Tillsats av alfentanil till propofol för PCS vid gynekologiska ingrepp i lokalbedövning ökade kirurgens möjlighet att operera utan avbrott eller med begränsad åtkomst, men bidrog till ökade risker. Kortare andningsuppehåll och behov av att ingripa för att återställa andningsfunktionen sågs hos dem som använt både alfentanil och propofol vid PCS. Patienternas upplevelser av perioperativ smärta och oro kan inte förklara de beräknade läkemedelskoncentrationerna. Istället verkar dessa bäst förklaras av typ av gynekologiskt ingrepp och patientens vikt. Patientens upplevda perioperativa smärta och oro vid endoskopiska undersökningar och behandlingar, är likartade till sin karaktär och intensitet när PCS används i jämförelse med narkossköterskestyrd sedering. PCS verkar inte heller vara mer tidskrävande och bidrar också till snabb återhämtning med en låg förekomst av trötthet, smärta och illamående.

Sammanfattningsvis kan patientkontrollerad sedering anpassas efter patient och aktuell undersökning/behandling för att sederingen ska vara både säker och ge bästa förutsättningar för en lyckad procedur. 


\section{Acknowledgments}

This thesis was carried out at the Department of Medical and Health Sciences, Division of Drug Research at Linköping University.

I would like to express my gratitude to everyone who supported me and contributed to this thesis. Friends, colleges, collaborators, co-authors, patients, staff - all of you have made it possible for me to complete this work.

Thank you to my supervisors, Lena Nilsson, Eva Uustal and Folke Sjöberg. Lena, my wise and insightful supervisor, thank you for the knowledge, the common sense, the rapid response in all matters and the true support in completing my thesis. Eva, my rational and enthusiastic supervisor, thank you for the clinical perspectives of science, the genuine work in making the best results for the patients and for the including attitude and the collaborations. I look forward to our upcoming projects. Folke, my visionary and elaborating supervisor, thank you for the never-ending inspiration and encouragement; you have made things happen and have responded with enthusiasm to my work, although it was not always excellent. Thank you helping me grow as an researcher. I look forward to our continuing collaboration at the Burn Unit.

Many thanks to Professor Christina Eintrei, at the division of anaesthesiology, EvaLena Zetterlund, director of the department of anaesthesiology and surgical care, Anna Nilsson and Thomas Åhlander, nursing chiefs, Metha Samuelsson, former nursing chief, and Karin Björnström-Karlsson, head of Operation Syd, for your decisions, encouragement and support in accepting me as a doctoral student. In addition, thank you for making it possible for me to combine all of the things I wanted to do and for making research a natural element for your staff members. 
Thank you to all the staff at the Burn Unit, the Gynaecological Out-patient Department and the Radiology Department for endoscopic procedures, for your professional attitudes towards my scientific work and for the helpful cooperation.

Thank you to researcher Ingrid Steinvall, for being an excellent scientist and for always being supportive in my questions and discussions of methods and statistics. Thank you for your enthusiasm and laughs - you are a star.

Thank you, Mats Fredrikson, statistician at the Linköping Academic Research Centre, for the excellent and hands-on courses, advice and support.

Thank you to the scientists and clinicians Kerstin Metcalf and Lottie Orvelius for the different perspectives of my work. You really made a difference.

Thank you Mary Evans, London, for the excellent language editing and improving my writing.

To all of my colleagues at Operation Syd who have been interested in my research, thank you for the supportive attitude and for taking care of the patients. You are true professionals, and I am inspired by your work.

Thank you to Mathilda Karlsson and Benjamin Grossmann, my collaborators and my friends, for the discussions, for the positive attitudes, for the interest in science and for the fun. I look forward to future collaborations.

To Katarina Berg and Elisabeth Ericsson, thank you for the discussions, encouragement and behind-the-scenes details. 
Thank you to Annelie Reinholdsson and Jonas Andersson, for all of the help with the economy and practicalities.

To my friends in Team Fillinge Ultra, thank you for the races, exercises and the part of life that is not research, writing or statistics. Thank you to Rune Larsson for showing that hard work and endurance capacity will pay off.

Without the support of my dear friends, near and distant, and my family this work would not have been completed. Thank you to my friends for the support, the interest in my work and for a rich life. To my parents, my sister, relatives and parents-in-law, thank you for the encouragement and for being there even if I was somewhere else, in reality or in my mind. Above all, thank you to my wife Malin for letting me be who I am, for believing in me, for the love, the support and the joyful life. To my sons, Alvar and Valter, thank you for reminding me of the things that matter, for your discussions about cars, kings and queens, snowboards, bones and animals, computers, travelling and other important and interesting topics. You are the best! 


\section{References}

1. American Society of Anesthesiologists. Continuum of depth of sedation: definition of general anesthesia and levels of sedation/analgesia. Available at the ASA website. https://www.asahq.org/For-Members/Standards-Guidelines-and-Statements.aspx Accessed 140915, 16:59.

2. American Society of Anesthesiologists Task Force on, S. and N.-A. Analgesia by, Practice guidelines for sedation and analgesia by non-anesthesiologists. Anesthesiology, 2002. 96(4): p. 1004-17.

3. Knape, J.T., et al., Guidelines for sedation and/or analgesia by non-anaesthesiology doctors. Eur J Anaesthesiol, 2007. 24(7): p. 563-7.

4. Kilgert, B., et al., Prospective Long-Term Assessment of Sedation-Related Adverse Events and Patient Satisfaction for Upper Endoscopy and Colonoscopy. Digestion, 2014. 90(1): p. 42-48.

5. $\quad$ Ramsay, M.A., et al., Sedation levels during propofol administration for outpatient colonoscopies. Proc (Bayl Univ Med Cent), 2014. 27(1): p. 12-5.

6. Chan, W.H., et al., Target-controlled infusion of propofol versus intermittent bolus of a sedative cocktail regimen in deep sedation for gastrointestinal endoscopy: comparison of cardiovascular and respiratory parameters. J Dig Dis, 2014. 15(1): p. 18-26.

7. Kawaai, H., et al., Intravenous sedation for implant surgery: midazolam, butorphanol, and dexmedetomidine versus midazolam, butorphanol, and propofol. J Oral Implantol, 2014. 40(1): p. 94-102.

8. Yen, P., et al., A comparison of fospropofol to midazolam for moderate sedation during outpatient dental procedures. Anesth Prog, 2013. 60(4): p. 162-77.

9. Kramer, K.J., et al., Comparison of propofol-remifentanil versus propofol-ketamine deep sedation for third molar surgery. Anesth Prog, 2012. 59(3): p. 107-17.

10. Sizlan, A., et al., Comparison of alfentanil and remifentanil infusions in combination with propofol for the outpatient extra-corporeal shock wave lithotripsy. Bratisl Lek Listy, 2011. 112(7): p. 380-4.

11. Kaygusuz, K., et al., A comparison of sedation with dexmedetomidine or propofol during shockwave lithotripsy: a randomized controlled trial. Anesth Analg, 2008. 106(1): p. 114-9, table of contents.

12. Tokumine, J., et al., Appropriate method of administration of propofol, fentanyl, and ketamine for patient-controlled sedation and analgesia during extracorporeal shock-wave lithotripsy. J Anesth, 2000. 14(2): p. 68-72. 
13. McGrane, O., et al., Procedural sedation with propofol: a retrospective review of the experiences of an emergency medicine residency program 2005 to 2010. Am J Emerg Med, 2012. 30(5): p. 706-11.

14. Uri, O., et al., Procedural sedation with propofol for painful orthopaedic manipulation in the emergency department expedites patient management compared with a midazolam/ketamine regimen: a randomized prospective study. J Bone Joint Surg Am, 2011. 93(24): p. 2255-62.

15. Denny, M.A., R. Manson, and D. Della-Giustina, Propofol and Etomidate are Safe for Deep Sedation in the Emergency Department. West J Emerg Med, 2011. 12(4): p. 399-403.

16. Zed, P.J., et al., Efficacy, safety and patient satisfaction of propofol for procedural sedation and analgesia in the emergency department: a prospective study. CJEM, 2007. 9(6): p. 4217.

17. Zacny, J.P., et al., Subjective and psychomotor effects of subanesthetic doses of propofol in healthy volunteers. Anesthesiology, 1992. 76(5): p. 696-702.

18. Solt, K. and S.A. Forman, Correlating the clinical actions and molecular mechanisms of general anesthetics. Curr Opin Anaesthesiol, 2007. 20(4): p. 300-6.

19. Campbell, S.G., et al., Procedural sedation and analgesia in a Canadian adult tertiary care emergency department: a case series. CJEM, 2006. 8(2): p. 85-93.

20. Sieg, A., et al., Safety analysis of endoscopist-directed propofol sedation: a prospective, national multicenter study of 24441 patients in German outpatient practices. J

Gastroenterol Hepatol, 2014. 29(3): p. 517-23.

21. Schuttler, J. and H. Ihmsen, Population pharmacokinetics of propofol: a multicenter study. Anesthesiology, 2000. 92(3): p. 727-38.

22. Taylor, M.B., et al., Ventilatory effects of propofol during induction of anaesthesia. Comparison with thiopentone. Anaesthesia, 1986. 41(8): p. 816-20.

23. Goodman, N.W., A.M. Black, and J.A. Carter, Some ventilatory effects of propofol as sole anaesthetic agent. Br J Anaesth, 1987. 59(12): p. 1497-503.

24. Larsen, R., et al., Effects of propofol on cardiovascular dynamics and coronary blood flow in geriatric patients. A comparison with etomidate. Anaesthesia, 1988. 43 Suppl: p. 25-31.

25. Van Aken, H., et al., The influence of fentanyl and tracheal intubation on the hemodynamic effects of anesthesia induction with propofol/N2O in humans. Anesthesiology, 1988. 68(1): p. 157-63.

26. Hillman, D.R., et al., Evolution of changes in upper airway collapsibility during slow induction of anesthesia with propofol. Anesthesiology, 2009. 111(1): p. 63-71. 
27. Dietis, N., D.J. Rowbotham, and D.G. Lambert, Opioid receptor subtypes: fact or artifact? Br J Anaesth, 2011. 107(1): p. 8-18.

28. Somogyi, A.A., D.T. Barratt, and J.K. Coller, Pharmacogenetics of opioids. Clin Pharmacol Ther, 2007. 81(3): p. 429-44.

29. O'Connor, A.B. and R.H. Dworkin, Treatment of neuropathic pain: an overview of recent guidelines. Am J Med, 2009. 122(10 Suppl): p. S22-32.

30. Metz, C., et al., Pharmacokinetics of human cerebral opioid extraction: a comparative study on sufentanil, fentanyl, and alfentanil in a patient after severe head injury. Anesthesiology, 2000. 92(6): p. 1559-67.

31. Maitre, P.O., et al., Population pharmacokinetics of alfentanil: the average dose-plasma concentration relationship and interindividual variability in patients. Anesthesiology, 1987. 66(1): p. 3-12.

32. Eberl, S., et al., Is "really conscious" sedation with solely an opioid an alternative to every day used sedation regimes for colonoscopies in a teaching hospital? Midazolam/fentanyl, propofol/alfentanil, or alfentanil only for colonoscopy: a randomized trial. Tech Coloproctol, 2014. 18(8): p. 745-52.

33. Schafer, S.L., P. Flood, and D.A. Schwinn, Chapter 19 Basic Principles of Pharmacology, in Miller's Anesthesia, R. Miller, Editor. 2010, Churchill Livingstone: Philadelphia.

34. Chun, S.Y., et al., Safety and efficacy of deep sedation with propofol alone or combined with midazolam administrated by nonanesthesiologist for gastric endoscopic submucosal dissection. Gut Liver, 2012. 6(4): p. 464-70.

35. Dumonceau, J.M., et al., European Society of Gastrointestinal Endoscopy, European Society of Gastroenterology and Endoscopy Nurses and Associates, and the European Society of Anaesthesiology Guideline: Non-anesthesiologist administration of propofol for GI endoscopy. Endoscopy, 2010. 42(11): p. 960-74.

36. Herrick, I.A., et al., Patient-controlled propofol sedation for elderly patients: safety and patient attitude toward control. Can J Anaesth, 1996. 43(10): p. 1014-8.

37. Lee, D.W., et al., The safety, feasibility, and acceptability of patient-controlled sedation for colonoscopy: prospective study. Hong Kong Med J, 2004. 10(2): p. 84-8.

38. Nilsson, A., et al., Alfentanil and patient-controlled propofol sedation - facilitate gynaecological outpatient surgery with increased risk of respiratory events. Acta Anaesthesiol Scand, 2012.

39. Oei-Lim, V.L., et al., Patient-controlled versus anesthesiologist-controlled conscious sedation with propofol for dental treatment in anxious patients. Anesth Analg, 1998. 86(5): p. 967-72. 
40. Gillham, M.J., et al., Patient-maintained sedation for ERCP with a target-controlled infusion of propofol: a pilot study. Gastrointest Endosc, 2001. 54(1): p. 14-7.

41. Galletly, D.C., T.G. Short, and P. Forrest, Patient-administered anxiolysis-- a pilot study. Anaesth Intensive Care, 1989. 17(2): p. 144-50.

42. Park, W.Y. and P.A. Watkins, Patient-controlled sedation during epidural anesthesia. Anesth Analg, 1991. 72(3): p. 304-7.

43. Rudkin, G.E., G.A. Osborne, and N.J. Curtis, Intra-operative patient-controlled sedation. Anaesthesia, 1991. 46(2): p. 90-2.

44. Cook, L.B., et al., True patient-controlled sedation. Anaesthesia, 1993. 48(12): p. 1039-44.

45. Murdoch, J.A. and G.N. Kenny, Patient-maintained propofol sedation as premedication in day-case surgery: assessment of a target-controlled system. Br J Anaesth, 1999. 82(3): p. 429-31.

46. Maslekar, S., et al., Randomized controlled trial of patient-controlled sedation for colonoscopy: Entonox vs modified patient-maintained target-controlled propofol. Colorectal Dis, 2011. 13(1): p. 48-57.

47. Osborne, G.A., et al., Intra-operative patient-controlled sedation. Comparison of patientcontrolled propofol with anaesthetist-administered midazolam and fentanyl. Anaesthesia, 1991. 46(7): p. 553-6.

48. Mazanikov, M., et al., A randomized comparison of target-controlled propofol infusion and patient-controlled sedation during ERCP. Endoscopy, 2013. 45(11): p. 915-9.

49. Joo, J.D., et al., The comparison of sedation quality, side effect and recovery profiles on different dosage of remifentanil patient-controlled sedation during breast biopsy surgery. Korean J Anesthesiol, 2012. 63(5): p. 431-5.

50. Bell, A., et al., A randomized controlled trial comparing patient-controlled and physiciancontrolled sedation in the emergency department. Ann Emerg Med, 2010. 56(5): p. 502-8.

51. Mandel, J.E., et al., A prospective, randomized, comparative trial evaluating respiratory depression during patient-controlled versus anesthesiologist-administered propofolremifentanil sedation for elective colonoscopy. Gastrointest Endosc, 2010. 72(1): p. 112-7.

52. Nilsson, A., et al., Patient controlled sedation using a standard protocol for dressing changes in burns: patients' preference, procedural details and a preliminary safety evaluation. Burns, 2008. 34(7): p. 929-34.

53. Agostoni, M., et al., Midazolam and pethidine versus propofol and fentanyl patient controlled sedation/analgesia for upper gastrointestinal tract ultrasound endoscopy: a prospective randomized controlled trial. Dig Liver Dis, 2007. 39(11): p. 1024-9. 
54. Lok, I.H., et al., A prospective randomized trial comparing patient-controlled sedation using propofol and alfentanil and physician-administered sedation using diazepam and pethidine during transvaginal ultrasound-guided oocyte retrieval. Hum Reprod, 2002. 17(8): p. 2101-6.

55. Rudkin, G.E., et al., Intra-operative patient-controlled sedation. Comparison of patientcontrolled propofol with patient-controlled midazolam. Anaesthesia, 1992. 47(5): p. 376-81.

56. Osborne, G.A., et al., Intra-operative patient-controlled sedation and patient attitude to control. A crossover comparison of patient preference for patient-controlled propofol and propofol by continuous infusion. Anaesthesia, 1994. 49(4): p. 287-92.

57. Lee, D.W., et al., Use of a variable-stiffness colonoscope decreases the dose of patientcontrolled sedation during colonoscopy: a randomized comparison of 3 colonoscopes. Gastrointest Endosc, 2007. 65(3): p. 424-9.

58. Wahlen, B.M., et al., Patient-controlled versus continuous anesthesiologist-controlled sedation using propofol during regional anesthesia in orthopedic procedures--a pilot study. Expert Opin Pharmacother, 2008. 9(16): p. 2733-9.

59. Singh, H., et al., Propofol for sedation during colonoscopy. Cochrane Database Syst Rev, 2008(4): p. CD006268.

60. Salomons, T.V., et al., Individual differences in the effects of perceived controllability on pain perception: critical role of the prefrontal cortex. J Cogn Neurosci, 2007. 19(6): p. 9931003.

61. Berns, G.S., et al., Neurobiological substrates of dread. Science, 2006. 312(5774): p. 754-8.

62. Koyama, T., et al., The subjective experience of pain: where expectations become reality. Proc Natl Acad Sci U S A, 2005. 102(36): p. 12950-5.

63. Girdler, N.M., et al., A prospective randomised controlled study of patient-controlled propofol sedation in phobic dental patients. Anaesthesia, 2000. 55(4): p. 327-33.

64. Westenskow, D.R., Fundamentals of feedback control: PID, fuzzy logic, and neural networks. J Clin Anesth, 1997. 9(6 Suppl): p. 33S-35S.

65. Shieh, J.S., et al., Pain model and fuzzy logic patient-controlled analgesia in shock-wave lithotripsy. Med Biol Eng Comput, 2002. 40(1): p. 128-36.

66. Beitz, A., et al., Capnographic monitoring reduces the incidence of arterial oxygen desaturation and hypoxemia during propofol sedation for colonoscopy: a randomized, controlled study (ColoCap Study). Am J Gastroenterol, 2012. 107(8): p. 1205-12. 
67. Chernik, D.A., et al., Validity and reliability of the Observer's Assessment of Alertness/Sedation Scale: study with intravenous midazolam. J Clin Psychopharmacol, 1990. 10(4): p. 244-51.

68. Ramsay, M.A., et al., Controlled sedation with alphaxalone-alphadolone. Br Med J, 1974. 2(5920): p. 656-9.

69. Rex, D.K., et al., Endoscopist-directed administration of propofol: a worldwide safety experience. Gastroenterology, 2009. 137(4): p. 1229-37; quiz 1518-9.

70. McQuaid, K.R. and L. Laine, A systematic review and meta-analysis of randomized, controlled trials of moderate sedation for routine endoscopic procedures. Gastrointest Endosc, 2008. 67(6): p. 910-23.

71. Glass, P.S., et al., Bispectral analysis measures sedation and memory effects of propofol, midazolam, isoflurane, and alfentanil in healthy volunteers. Anesthesiology, 1997. 86(4): p. 836-47.

72. Liu, J., H. Singh, and P.F. White, Electroencephalographic bispectral index correlates with intraoperative recall and depth of propofol-induced sedation. Anesth Analg, 1997. 84(1): p. $185-9$.

73. Kearse, L.A., Jr., et al., Bispectral analysis of the electroencephalogram correlates with patient movement to skin incision during propofol/nitrous oxide anesthesia. Anesthesiology, 1994. 81(6): p. 1365-70.

74. Beecroft, J.M. and P.J. Hanly, Comparison of the OxyMask and Venturi mask in the delivery of supplemental oxygen: pilot study in oxygen-dependent patients. Can Respir J, 2006.

13(5): p. 247-52.

75. Aldrete, J.A., The post-anesthesia recovery score revisited. J Clin Anesth, 1995. 7(1): p. 8991.

76. Schnider, T.W., et al., The influence of method of administration and covariates on the pharmacokinetics of propofol in adult volunteers. Anesthesiology, 1998. 88(5): p. 1170-82.

77. Schnider, T.W., et al., The influence of age on propofol pharmacodynamics. Anesthesiology, 1999. 90(6): p. 1502-16.

78. Scott, J.C. and D.R. Stanski, Decreased fentanyl and alfentanil dose requirements with age. A simultaneous pharmacokinetic and pharmacodynamic evaluation. J Pharmacol Exp Ther, 1987. 240(1): p. 159-66.

79. Coimbra, C., M. Choiniere, and T.M. Hemmerling, Patient-controlled sedation using propofol for dressing changes in burn patients: a dose-finding study. Anesth Analg, 2003. 97(3): p. 839-42. 
80. Maurice-Szamburski, A., et al., Effect of patient-controlled sedation with propofol on patient satisfaction: a randomized study. Ann Fr Anesth Reanim, 2013. 32(12): p. e171-5.

81. Kindler, C.H., et al., The visual analog scale allows effective measurement of preoperative anxiety and detection of patients' anesthetic concerns. Anesth Analg, 2000. 90(3): p. 70612.

82. Mazanikov, M., et al., Patient-controlled sedation with propofol and remifentanil for ERCP: a randomized, controlled study. Gastrointest Endosc, 2011. 73(2): p. 260-6.

83. Thorpe, S.J., V.R. Balakrishnan, and L.B. Cook, The safety of patient-controlled sedation. Anaesthesia, 1997. 52(12): p. 1144-50.

84. Mazanikov, M., et al., Patient-controlled sedation for ERCP: a randomized double-blind comparison of alfentanil and remifentanil. Endoscopy, 2012. 44(5): p. 487-92.

85. Lysakowski, C., et al., Effects of fentanyl, alfentanil, remifentanil and sufentanil on loss of consciousness and bispectral index during propofol induction of anaesthesia. Br J Anaesth, 2001. 86(4): p. 523-7.

86. Mertens, M.J., et al., Mixed-effects modeling of the influence of alfentanil on propofol pharmacokinetics. Anesthesiology, 2004. 100(4): p. 795-805.

87. Mertens, M.J., et al., Propofol alters the pharmacokinetics of alfentanil in healthy male volunteers. Anesthesiology, 2001. 94(6): p. 949-57.

88. Mandel, J.E., et al., A randomized, controlled, double-blind trial of patient-controlled sedation with propofol/remifentanil versus midazolam/fentanyl for colonoscopy. Anesth Analg, 2008. 106(2): p. 434-9, table of contents.

89. Qadeer, M.A., et al., Propofol versus traditional sedative agents for gastrointestinal endoscopy: a meta-analysis. Clin Gastroenterol Hepatol, 2005. 3(11): p. 1049-56.

90. Alhashemi, J.A. and A.M. Kaki, Anesthesiologist-controlled versus patient-controlled propofol sedation for shockwave lithotripsy. Can J Anaesth, 2006. 53(5): p. 449-55.

91. Evans, E.N., K. Ganeshalingam, and P. Ebden, Changes in oxygen saturation and transcutaneous carbon dioxide and oxygen levels in patients undergoing fibreoptic bronchoscopy. Respir Med, 1998. 92(5): p. 739-42.

92. Janssens, J.P., et al., Non-invasive (transcutaneous) monitoring of PCO2 (TcPCO2) in older adults. Gerontology, 2005. 51(3): p. 174-8.

93. Palmisano, B.W. and J.W. Severinghaus, Transcutaneous PCO2 and PO2: a multicenter study of accuracy. J Clin Monit, 1990. 6(3): p. 189-95. 
94. Tremper, K.K. and S.J. Barker, Transcutaneous oxygen measurement: experimental studies and adult applications. Int Anesthesiol Clin, 1987. 25(3): p. 67-96.

95. Paspatis, G.A., et al., Synergistic sedation with oral midazolam as a premedication and intravenous propofol versus intravenous propofol alone in upper gastrointestinal endoscopies in children: a prospective, randomized study. J Pediatr Gastroenterol Nutr, 2006. 43(2): p. 195-9.

96. VanNatta, M.E. and D.K. Rex, Propofol alone titrated to deep sedation versus propofol in combination with opioids and/or benzodiazepines and titrated to moderate sedation for colonoscopy. Am J Gastroenterol, 2006. 101(10): p. 2209-17.

97. Chung, K.C., et al., The effect of pre-procedure anxiety on sedative requirements for sedation during colonoscopy. Anaesthesia, 2013. 68(3): p. 253-9.

98. Hong, J.Y., Y.S. Jee, and F.W. Luthardt, Comparison of conscious sedation for oocyte retrieval between low-anxiety and high-anxiety patients. J Clin Anesth, 2005. 17(7): p. 54953.

99. Joo, H.S., et al., A comparison of patient-controlled sedation using either remifentanil or remifentanil-propofol for shock wave lithotripsy. Anesth Analg, 2001. 93(5): p. 1227-32.

100. Frolich, M.A., et al., Precision and bias of target controlled propofol infusion for sedation. Br J Anaesth, 2005. 94(4): p. 434-7.

101. Enlund, M., TCI : Target controlled infusion, or totally confused infusion? Call for an optimised population based pharmacokinetic model for propofol. Ups J Med Sci, 2008. 113(2): p. 161-70.

102. Rodrigo, M.R., et al., Patient maintained propofol sedation for dental surgery. Int Dent J, 2004. 54(4): p. 177-81.

103. Chapman, R.M., et al., Evaluation of a new effect-site controlled, patient-maintained sedation system in dental patients. Anaesthesia, 2006. 61(4): p. 345-9.

104. Campbell, L., et al., Patient maintained sedation for colonoscopy using a target controlled infusion of propofol. Anaesthesia, 2004. 59(2): p. 127-32.

105. Mandel, J.E. and E. Sarraf, The variability of response to propofol is reduced when a clinical observation is incorporated in the control: a simulation study. Anesth Analg, 2012. 114(6): p. 1221-9.

106. Koo, B.N., et al., A pharmacodynamic analysis of factors affecting recovery from anesthesia with propofol-remifentanil target controlled infusion. Acta Pharmacol Sin, 2012. 33(8): p. 1080-4. 
107. Lee, D.W., et al., Patient-controlled sedation versus intravenous sedation for colonoscopy in elderly patients: a prospective randomized controlled trial. Gastrointest Endosc, 2002. 56(5): p. 629-32.

108. Crepeau, T., et al., Significance of patient-controlled sedation during colonoscopy. Results from a prospective randomized controlled study. Gastroenterol Clin Biol, 2005. 29(11): p. 1090-6.

109. Cork, R.C., et al., Effect of patient-controlled sedation on recovery from ambulatory monitored anesthesia care. Am J Anesthesiol, 1995. 22(2): p. 94-100.

110. Maple, J.T., et al., Carbon dioxide insufflation during ERCP for reduction of postprocedure pain: a randomized, double-blind, controlled trial. Gastrointest Endosc, 2009. 70(2): p. 27883.

111. Aldrete, J.A., Modifications to the postanesthesia score for use in ambulatory surgery. $\mathrm{J}$ Perianesth Nurs, 1998. 13(3): p. 148-55.

112. Kleinbeck, S.V., Self-reported at-home postoperative recovery. Res Nurs Health, 2000. 23(6): p. 461-72.

113. http://www.sfai.se/riktlinjer/procedurrelaterad-propofolsedering. 


\section{Papers}

The articles associated with this thesis have been removed for copyright reasons. For more details about these see:

http://urn.kb.se/resolve?urn=urn:nbn:se:liu:diva-112372 